January 2002

\title{
Geography, Demography, and Early Development
}

\author{
Murat F. Iyigun \\ University of Colorado, Boulder \\ murat.iyigun@stripe.colorado.edu
}

\begin{abstract}
This paper explores the role of geography in economic development and demographic transition. It presents a growth model where survival is endogenously determined and where the odds of survival and the returns to labor are higher in geographically favorable regions. Higher life expectancy prompts parents to devote more of their resources to old-age consumpion and enjoyment. Consequently, they invest relatively more in the quantity and quality of their offspring. Investment in education, together with population growth, eventually triggers technological progress. As the level of technology improves and life expectancy rises along with it, a geographically advantageous economy first enters a post-Malthusian regime during which both fertility and educational attainment increase. Then, as further improvements in technology lead to a higher education premium, such an economy undergoes a demographic transition during which life expectancy continues to rise and parents have fewer but more educated children. In regions where geography is more adverse, this transition does not take place and economies remain trapped in the Malthusian regime. Thus, accounting for the role of geography in development helps to link demographic transition to geography and shows that the latter affects the economy mostly indirectly through the impact of geography on households' demographic choices. In the early stages of development, those choices in turn determine whether economies attain the scale and scope necessary for sustained economic progress. The paper also provides a framework with which to assess why geography may matter less today.
\end{abstract}

Keywords: Human Capital, Demographic Transition, Growth, Geography. JEL Classification Numbers: J13, O11, O33, O40.

For useful comments and suggestions I thank Daron Acemoglu, Martin Boileau, Ann Carlos, Phil Graves, Herschel Grossman, and Naci Mocan. The standard disclaimer applies. Please send all correspondence to Murat Iyigun, University of Colorado at Boulder, Department of Economics, Campus Box 256, Boulder, CO 80309-0256. Phone: (303) 492-6653. Fax: (303) 492-8622. 


\section{Introduction}

There is a recent debate about the role of geography versus that of institutions in economic progress. This debate revolves primarily around whether geographic characteristics or institutions account for the contemporary cross-country differences in economic prosperity, and there is a growing body of evidence to shed doubt on a direct geography effect. ${ }^{1}$ Nonetheless, most findings to date are consistent with the view that geography was important in the emergence of agriculture and early development. ${ }^{2}$ Moreover, there exist inextricable links between economic development and demographic trends in the very long run. ${ }^{3}$ This paper presents a unified, very long run economic growth theory that focuses on geography. By doing so, it links early development and demographic transition to geography and demonstrates that the latter affects economic development mostly indirectly-through the impact of geography on households' demographic choices. Those choices, which entail the quantity and the quality of offspring, in turn determine whether economies eventually attain the scale and scope necessary for sustained technological progress. The framework presented also provides an assessment of why geography may matter less today.

The 20th century witnessed an astounding change in the standards of living in the Western Hemisphere. Conservative estimates show, for example, that the average income in the United States rose tenfold in the last 125 years. Sharp increases in educational attainment, improvements in life expectancy, and significant declines in fertility and mortality also characterized this period of rapid wealth accumulation in "Industrialized countries."

Two facts make this progress all the more remarkable: First, there exist huge disparities in economic conditions across the world today. A highly publicized estimate by the World Bank shows, for example, that roughly one billion people still live on less than one dollar a day. ${ }^{4}$ And the per capita incomes of rich industrialized nations are roughly 25 times those of the poor sub-Saharan African economies. The existing wide gap in the cross-country income distribution is, for the most part, a manifestation of the

\footnotetext{
${ }^{1}$ For recent evidence and an extensive survey of the literature on the geography versus institutions debate, see Acemoglu, Johnson, and Robinson (2001).

${ }^{2} \mathrm{McNeill}$ (1998, p. 67) claims that the reason why Africa remained backward in the development of agricult ure compared to temperate lands is that the latter exacted much lower costs in terms of exposure to disease.

${ }^{3}$ See, for example, Galor and Weil (2000), Galor and Moav (2000), and Jones (2001).

${ }^{4}$ See, for example, Dollar and Kraay (2001).
} 
sustained economic progress that took place in Europe and some of its offshoots in the last century. Second, human existence for the most part was synonymous with misery. Even after human societies settled down to create the first agrarian economies around 10,000 B.C., living conditions did not change significantly. For nearly 12,000 years after the First Agrarian Revolution, the economic environment remained stagnant. During that long period, higher economic output due to slight improvements in the sophistication of existing technologies or milder climate conditions generated higher fertility and more rapid population growth. With limited amount of fixed resources, such as agricultural land, and relatively primitive technologies prior to the Industrial Revolution, faster population growth guaranteed that improvements in the standards of living would be short-lived. In the long run, this in turn meant that the size of the population would remain relatively flat. This was unambiguously the case for most of human existence: In the period between 100,000 B.C. and 10,000 B.C., the annual world population growth rate is estimated to have been 0.0016 percent a year. In the roughly 11,500 year period between the First Agrarian Revolution and 1500 A.D., world population grew from about 6 million to 425 million. That translates into a less than 0.04 percent annual population growth rate over that time. ${ }^{5}$

As late as the 18th century this cycle had not yet been broken. In 1798, Thomas Malthus made his famous prediction that fertility and birth rates would always respond positively to higher incomes and thus would ensure that economic prosperity and human population would be bound by the limited amount of global resources. Since then, however, a remarkable transition that rendered the Malthusian world obsolete has taken place. In the "post-Malthusian" era, population growth rates rose sharply in response to rising per capita incomes. As a consequence, the world population exploded to reach 6 billion at the end of the 20th century from about 1 billion one hundred years ago. In Europe and its offshoots where per capita incomes have risen sharply since the Industrial Revolution, population growth rates initially responded positively by averaging 0.4 percent between 1700 and 1820, and 0.7 percent between 1820 and 1900. By the early 20th century, the Industrialized countries had entered a new "demographic transition" era during which per capita income growth kept rising, and population growth surprisingly began declining. These demographic changes, which contradicted those predicted by the Malthusian model, have consequently led modern economists to develop theories that

\footnotetext{
${ }^{5}$ See Maddison (1982), Livi-Bacci (1997), and Weil (2001).
} 
show how technological progress and higher returns to education might lead households to have fewer but more educated children. ${ }^{6}$ One of the major tasks that remained, however, was reconciling the Malthusian predictions with those of the modern development theories. In recent years, unified growth and development theories that address this issue have emerged. Primary among those are Galor and Weil (2000), Galor and Moav (2000), and Jones (2001). ${ }^{7}$

In this paper, I contribute to this emergent and important literature by highlighting the role of geography in the very long-run evolution of human kind. The novelty of my approach is the emphasis on geography, warranted by two related findings: First, geographic characteristics were important in the emergence of agriculture and early development. Second, economic development and demographic trends are related in the very long run. Taken together these findings suggest that accounting for the role of geography in the evolution of human societies could be important. And the reason is that, by influencing the odds of survival and life expectancy at least in the early stages of development, geography has the potential to affect many household choices-including but not confined to those regarding the quantity and quality of offspring.

In order to incorporate the role of geography into development and demographics, I present an overlapping generations model in which technological progress, fertility, and life expectancy are all endogenously determined. In geographically favorable regions survival odds are higher. Parents in such areas expect to live longer compared to individuals who live in less hospitable regions. This in turn prompts them to allocate more of their resources to old-age consumption and enjoyment. Hence, higher life expectancy makes parents invest more in both the quantity and quality of their offspring. In regions where geographical characteristics are more adverse, individuals struggle for survival. These parents devote all of their limited resources to consumption and to having children. They do not invest in the education of their young. As a result, economies in geographically disadvantageous regions never escape the Malthusian trap: Technology remains primitive, life expectancy and population growth low, and mortality high.

\footnotetext{
${ }^{6}$ See, for example, Becker, Murphy and Tamura (1990), Galor and Weil (1996), and Iyigun (2000).

${ }^{7}$ More broadly, these papers fall within a strand of the literature that focuses on the process of economic growth in the very long run. This broader strand includes, among others, papers by Kremer (1993) and Hansen and Prescott (2000). However, unlike the paper presented here and the ones listed above, these papers either do not completely endogenize the processes of technological change and population growth or do not generate the demographic transition from the Malthusian model to the modern regime.
} 
In geographically favorable regions, however, a different story unfolds. Since existing technologies are not very sophisticated during the initial stages of development, life expectancy, fertility and the average education levels remain relatively low even in these regions. But steady population growth and investment in education combine to eventually trigger a process of technological change. This in turn improves life expectancy further and geographically favorable economies enter the post-Malthusian phase during which both fertility and educational attainment increase. And eventually, as technologies become more sophisticated and the returns to education rise along with it, a geographically advantageous area enters the demographic transition regime under which life expectancy and educational attainment continue to rise, but parents start to have fewer children.

In this model, the sophistication of existing technologies affects fertility and education via two channels. First, the "life-expectancy" effect: Because technological progress leads to higher incomes, it improves the likelihood that any given individual will survive to live longer. And this manifests itself through a shift in the amount of total resources allocated to old-age enjoyment, the result of which includes-but is not confined to-having more children. Second, the "education-premium" effect: A more sophisticated technology raises the return to education and encourages parents to shift from quantity towards quality. Thus, fertility rates will first rise and then fall over the course of economic development if the life-expectancy effect dominates in the early stages of development and the education-premium effect influences its later stages. ${ }^{8}$ This, in fact, is what generates the regime shift from the post-Malthusian era-during which per capita incomes and population growth rates were positively related-to the demographic transition regime--where the relationship between per capita income and fertility rates have reversed.

In addition to generating the very-long-run relationship between technological change and demographic transition from the Malthusian regime to the modern one, an emphasis on geography in a unified growth framework provides further insights. For

\footnotetext{
${ }^{8}$ There are both empirical and theoretical underpinnings of such a mechanism. Goldin and Katz (1998), for example, find evidence that the technology-skill complementarity originated with the shift in manufacturing to batch and continuous-process methods, as well as the adoption of electricity motors. All of those occured in the 1890s and beyond-well after life expectancy began to rise dramatically in the late-18th and early-19th centuries due to better nutrition (see McNeill, 1998).

Acemoglu (1998) presents a model in which the direction of technical change is determined endogenously according to the fraction of skilled (or educated) workers in the economy. Thus, his approach provides a theoretical basis for which to believe that the effects of the technology-skill complementarity becomes more pronounced later during the development process.
} 
example, it demonstrates why the roots of modern civilization lie in the geographically advantageous climates of Eurasia; how geographical adversity manifests itself in a struggle for survival where life expectancy remains low and individuals devote a disproportionate amount of their limited resources to sustenance and procreation; and why the emergence of institutions that promote technology adoption might diminish the role of geography in development and demography.

As I alluded to earlier, this paper is most related to the unified growth models. Galor and Weil (2000) develop a framework that focuses primarily on the link between human capital accumulation and technological progress. In their model, economies eventually escape the Malthusian trap because of the scale effects of population size on technological progress. Galor and Moav (2000) argue that the process of natural selection gives individuals who value relatively more the quality of their offspring a survival advantage. They then demonstrate that the emergence of mutations that value child quality more is sufficient to kick start a phase of demographic transition and economic development that is consistent with those observed in modern developed economies. Jones (2001) combines the human capital-based theory of economic growth with endogenous fertility and mortality to demonstrate that the very-long term patterns of economic development and demographic change can be generated in the presence of two external shocks-improvements in property rights and temporary declines in total productivity. The present effort differs from these papers by its emphasis on geographic characteristics as the driving force behind the patterns of demographic change and economic development that took place throughout human history.

This model is also related to empirical work that addresses-directly or indirectlywhether geographic characteristics or institutional features primarily impact economic performance. Gallup, Sachs, and Mellinger (1999) and Sachs (2000, 2001) find that location and climate have large effects on the level and growth of incomes per capita because they impact agricultural productivity, disease burdens, and transport costs. In contrast, Acemoglu, Johnson and Robinson (forthcoming, 2001) argue that the simple geography hypothesis, which suggests a direct link between climate and economic development, is inconsistent with available historical data. Their findings instead show that institutional differences help to explain most of the cross-country variation in incomes. Hall and Jones (1999) demonstrate how, while geographic location helps to account for a significant portion of the cross-country differences in output per worker, at least some 
of this might be due to the indirect role of geography in shaping institutions. What I present below differs from these papers on two important accounts: First, my approach is almost purely theoretical. And second, my emphasis on geography over the very long run helps to identify that geography affects the economy mostly indirectly via its impact on economic decisions and demographics.

\section{The Building Blocks}

The model rests on the following key assumptions:

I) Geographic characteristics affect labor productivity. Hall and Jones show that temperate climates positively affect productivity and that geography helps to explain at least some of the 369 percent variation in output per worker between the most and least favorably located countries. In a similar vein, Gallup et al. demonstrate that the one channel through which climate has a positive effect on both the level and growth of incomes is via agricultural productivity. Masters and McMillan (2001) show that, since the early 1960s, temperate countries have converged towards higher levels of income due, at least in part, to their climates while tropical nations have converged towards various levels of income. Diamond (1998) is a recent but influential book that also addresses this topic. It provides evidence that local geographic conditions, such as climate, the availability of domesticable plants and animals, proximity to abundant natural resources help to explain why many civilizations in history have emerged in geographically favorable regions. And Jones (1981) notes "income per capita was higher in Europe than in Asia partly because natural disasters were fewer."

II) Endogenous survival odds. In this model, the odds of survival (or mortality) are determined endogenously according to individuals' incomes. Specifically, I consider an overlapping generations model in which individuals could live up to three periods and assume that there exists uncertainty about survival during the final old-age period. ${ }^{9}$ This formulation has its analogs in other work. For example, a more discrete version of

\footnotetext{
${ }^{9}$ There are at least two alternative specifications of survival probability. First, one could assume that survival depends not on income but consumption. Then, in determining their optimal consumption pattern and the amount of resources devoted to their children, individuals would have to take into account not only the marginal utility of consumption but also the marginal effect of consumption on their own survival. This specification, unlike the one I choose to present here, would not allow closed form solutions but its qualitative results would be similar to what is below. Second, while I abstract from child mortality and focus on adult mortality only, the model could be extended to include the former without significantly altering the qualitative nature of the main results.
} 
this approach has its precedents in models where consumption below a subsistence level leads to extinction. This is in fact the approach taken by Galor and Weil, Galor and Moav, and Jones (2001). Also there exists papers in which survival is modeled in similar fashion to the one presented below. ${ }^{10}$

Since (I) links individuals' incomes to geographic characteristics, the idea that incomes influence survival also implies that mortality should be higher if the climate is adverse and natural resources are scarce. ${ }^{11}$ Indeed, Wrigley and Schofield (1989) find that mortality in England between 1541 and 1871 was increased by unusually cold temperatures in winter and by extremely hot temperatures in summer. Jones (1981) discusses that a hot environment of human and animal diseases in Africa kept the rates of mortality high and the level of population down.

III) Parents value both the quantity and quality of offspring. Individuals in this model operate in the traditional Beckerian mold. ${ }^{12}$ That is, household fertility is driven by a utility function that has as its arguments individuals' own consumption as well as the quantity and quality of their offspring. Given this Beckerian quality-quantity tradeoff, parents devote a larger fraction of their incomes to their children (either in the form of more or better educated offspring) as their self-survival odds improve due to technological change.

IV) Technological progress raises the return to education. While combining endogenous survival with the quality-quantity tradeoff is important in generating a higher fraction of income being devoted to the offspring, it does not yield the result that the optimal number of children first increases and then decreases as the level of technology improves. Rather, the mechanism that generates a decline in fertility is driven by higher returns to education due to improvements in technology. Indeed, Nelson and Phelps (1966) and Schultz (1975) provide ample evidence that suggests this is the case. Bartel and Lichtenberg (1991) and Bartel and Sicherman (1999) show that industries that use new technologies pay higher wages to workers with the same levels of experience and education than industries that use older technology. There is also evidence that technological

\footnotetext{
${ }^{10}$ See, for example, Grossman and Mendoza (2000).

${ }^{11}$ This, of course, is associated with the "positive check" on population growth identified by Malthus. He envisaged two sets of relationships that might serve to keep a population in balance with its economic resources. In both cases, an increase in population exerts pressure on food prices and lowers real incomes. Positive check operates through increases in mortality, and the preventive check manifests itself in lower nuptiality and fertility. Refer to Wrigley and Schofield (1989, pp. 458-466) for more details.

${ }^{12}$ Becker (1981).
} 
progress increases the return to an unobservable component of skill not accounted for by education and experience. ${ }^{13}$ Juhn, Murphy, and Brooks (1993) demonstrate that the reward to the unobservable component of skills has increased over the period 1963-1989, a period which witnessed the implementation of many new technologies.

V) Human capital and population size affect the pace of technological progress. Finally, I employ the hypothesis that the stock of human capital (or the average education level) of an economy and its population size positively influence its rate of technological progress. The link between human capital and technological change is crucial in my model as it accounts for the mechanism that sustains technological progress and generates-via changes in the education premium-the demographic transition. ${ }^{14}$ The link between population size and technological progress captures the idea that, for a given level of education, a larger population generates greater demand and supply and more rapid diffusion of ideas. That technological change is also linked to population size, a la Kremer (1993) and Galor and Weil (2000), is not as essential for the qualitative results below although it helps to delay the onset of the transition from the Malthusian state to the modern one.

In the following two sections, I incorporate these assumptions into an endogenous growth model and examine their implications for economic development and demographic trends. In Section 5, I discuss how the emergence of institutions that promote technology transfers would render geography less important. In Section 6, I calibrate some numerical examples. In section 7, I summarize the model's main implications. And in Section 8, I conclude.

\section{The Economy}

\subsection{Production}

Consider an overlapping generations economy in which real economic activity extends over an infinite discrete time. In every period the economy produces a single homogenous good using efficiency units of labor. The supply of aggregate efficiency units of labor is determined by the size of the work force and the human capital inherent in each worker.

\footnotetext{
${ }^{13}$ Galor and Tsiddon (1997) review several other studies that support the idea that technological progress increases the return to ability (unobservable component of human capital) in addition to the ones mentioned here.

${ }^{14}$ For surveys of the human capital and technological change link, see for example, Nelson and Phelps, Schultz, and Bartel and Lichtenberg (1987).
} 
Let $Y_{t}^{j}$ denote the aggregate output at time $t$ of an economy located in geographic region j. Then,

$$
Y_{t}^{j}=A_{t} G^{j} H_{t}^{j}
$$

where $A_{t}$ represents the endogenously determined technology level in period $t, G^{j}$ is a parameter that measures the hospitability of region $j$ to output production, and where $H_{t}^{j}$ is the efficiency units of labor supply. ${ }^{15}$

By assumption there are no property rights over $G$ and its rate of return is zero. The labor market is competitive and human capital is paid its marginal product: ${ }^{16}$

$$
w_{t}=A_{t} G
$$

\subsection{Individuals}

Individuals, who are identical, live for up to three periods in overlapping generations. All individuals survive youth and young adulthood but only some live to become old. Although there is uncertainty about who reaches old age, a higher level of income improves the survival odds. Each individual has a single parent and is endowed with a unit of time in every period. When young, a member of generation $t-1$ consumes a fraction of her parent's time. This time requirement increases with the child's education level. In the second period of life, $t$, the individual is a young adult. During this period she works, consumes, and procreates, allocating her time between employment and child rearing. In the final old-age period, $t+1$, the individual retires and consumes if she survives to live that long.

\footnotetext{
${ }^{15}$ For simplicity of notation, I will supress the geography superscript $j$ hereafter unless the discussion warrrants its inclusion.

${ }^{16} \mathrm{By}$ assuming there are constant returns to human capital, the model abstracts from how changes in the level of population might influence wage rates. In fact, the negative link between the size of the labor force and wage rates provided the main channel through which the positive and preventive Malthusian checks operated (see footnote 11). The model presented here could be easily extended to ensure that population shocks lead to changes in the real wage rate, and therefore, that short-run deviations from the subsistence equilibrium self-correct in the medium run.
} 


\subsubsection{Preferences and Budget Constraints}

Individuals' preferences are defined over their expected consumption and the quantity and quality of children that they have. Resources that are devoted to improving genetic survival-via quantity and/or quality investment in the offspring-reduce the availability of resources for consumption. Let $c_{t}^{t-1}$ and $c_{t+1}^{t-1}$ respectively denote the consumption of a member of generation $t-1$ in young adulthood and old age. And let $n_{t}^{t-1}$ and $I_{t+1}^{t}$ respectively denote the number of her children and their average future income. Preferences of this individual are represented by the following inter-temporal utility function:

$$
U^{t-1}=\ln c_{t}^{t-1}+\alpha p_{t+1} \ln c_{t+1}^{t-1}+\left(1+p_{t+1}\right)\left[\beta \ln n_{t}^{t-1}+(1-\beta) \ln I_{t+1}^{t}\right] ;
$$

where $\alpha \in(0,1)$, and $\beta \in(1 / 2,1)$. In (3), the parameter $\alpha$ measures the rate of consumption time preference, $\beta$ the value associated with the number of offspring relative to average quality as measured by future income, and $p_{t+1}, 0 \leq p_{t+1} \leq 1$, the probability of surviving young adulthood. ${ }^{17}$ The latter is an increasing, concave function of income. That is, $p_{t+1}=p\left(I_{t}^{t-1}\right)$. I assume that this probability satisfies the following properties: $p^{\prime}>0, p^{\prime \prime}<0, p(0)=0, p(\infty)=\bar{p} \leq 1, \lim _{I \rightarrow 0} p^{\prime}=\infty$, and $\lim _{I \rightarrow \infty} p^{\prime}=0$. Note also that the life expectancy of all individuals in this economy equals $2+p_{t+1}$.

Following the standard Beckerian model of household fertility, individuals decide the optimal number of their children and the education level of each subject to a budget constraint that reflects the allocation of time between work and child rearing. To formalize, let $e_{t+1}$ denote the education level of each child, and let $\tau^{n}$ and $\tau^{e}$ respectively denote the time costs of rearing a child and educating one for a unit of time. Then, for a member of generation $t-1, n_{t}\left(\tau^{n}+\tau^{e} e_{t+1}\right)$ denotes the total time cost of child rearing and education.

Given that a member of generation $t-1$ works in the following period and possesses $h_{t}$ efficiency units of labor at that time, her income, $I_{t}$, is equal to $w_{t} h_{t}$. She allocates this potential income among current consumption, saving for future consumption and child rearing and education. Thus, she faces the following budget constraint:

\footnotetext{
${ }^{17}$ Note that both the number and the average expected income of an individuals' offspring do not change during adulthood. Hence, $n_{t+1}^{t-1}=n_{t}^{t-1}$ and $I_{t+2}^{t}=I_{t+1}^{t}$. Hereafter, I will also suppress superscripts that identify generations unless the specific reference requires their explicit notation.
} 


$$
w_{t} h_{t} n_{t}\left(\tau^{n}+\tau^{e} e_{t+1}\right)+c_{t}+S_{t} \leq w_{t} h_{t}=I_{t}
$$

where $S_{t}$ denotes the individual's amount of saving in period $t .^{18}$

\subsubsection{Population, Education, and Technological Progress}

The size of the working population at time $t+1, L_{t+1}$, is given by

$$
L_{t+1}=n_{t} L_{t}
$$

where $L_{t}$ is the working population in period $t, n_{t}$ is the number of children per parent, and $n_{t}-1$, is the growth rate of the working population. ${ }^{19}$ The size of the population at time $0, L_{0}$, is given historically.

In order to employ a relatively simple human capital accumulation process, I emphasize only the notion that the sophistication of existing technologies affects the returns to education. ${ }^{20}$ In particular, I assume that each person's human capital is determined in the following specific way:

$$
h_{t+1}=1+\phi_{t} e_{t+1} ; \quad \phi_{t}=\phi\left(A_{t}\right)
$$

where $\forall A_{t}>0, \phi\left(A_{t}\right)>0, \phi^{\prime}>0$, and $\phi^{\prime \prime} \leq 0 .{ }^{21}$ According to (6), the child's level of human capital is equal to one when her parent devotes no time to her education.

At any given time $t+1$, I assume that technological progress is endogenously determined by the average education level of workers, $e_{t}$, and the size of the working population, $L_{t}$. That is,

\footnotetext{
${ }^{18} \mathrm{I}$ assume that there exists a costless storage technology that allows individuals to transfer part of their current potential consumption to the future.

${ }^{19}$ Note that, at any given time $t$, total population equals $\left[1+n_{t}+p_{t} / n_{t-1}\right] L_{t}$. This suggests that total population would equal $3 L_{t}$ if the growth rate of population was zero and the odds of survival were one.

${ }^{20} \mathrm{Of}$ course, by doing so I abstract from various channels through which the level of parental human capital or the rate of technological progress can potentially affect human capital formation. See Galor and Tsiddon (1997) for a detailed survey. The qualitative nature of the results are invariant to the inclusion of these variables.

${ }^{21}$ The assumption that the marginal product of human capital is constant is also made for convenience only and does not alter the main results.
} 


$$
\frac{A_{t+1}-A_{t}}{A_{t}} \equiv g_{t+1}=g\left(e_{t}, L_{t}\right)
$$

where $\forall e_{t}>0$, and $\forall L_{t}>L^{*}>0, g\left(e_{t}, L_{t}\right)>0, g_{e}, g_{L}>0, g_{e e}, g_{L L} \leq 0$, and where $\forall e_{t}>0$ and $\forall L_{t} \leq L^{*}, g\left(e_{t}, L_{t}\right)=0$. The above specification implies that for a strictly positive average education level and a sufficiently large population size, the rate of technological progress is positive. Otherwise, if the average education level of the working age population is zero or the size of the population is relatively small, the rate of technological progress is zero. ${ }^{22}$ Like the size of the population, the level of the technology at time $0, A_{0}$, is also given historically.

One could think of the variable $A_{t}$ more broadly to cover the impact of institutions such as the legal and financial system, property rights and intellectual property on productive activities. Then the formulation in (7) would suggest that the creation of more effective institutions over time are also driven by the average education level of the economy-once the level of population reaches a certain threshold.

\subsubsection{Geography, Life Expectancy, and the Quantity-Quality Tradeoff}

Members of generation $t-1$ maximize (3) by choosing the number and education of their offspring, and their own optimal consumption pattern. Substituting equations (2), (4), and (6) into (3), and expressing the amount of saving, $S_{t}^{t-1}$, as a fraction of total potential income (i.e., $S_{t}=s_{t} w_{t} h_{t}$ ), the problem of a representative individual can be written as follows:

\footnotetext{
${ }^{22}$ This formulation is identical to the one employed by Galor and Weil (2000) and is designed to incorporate the role of scale effects in technological progress a la Kremer. As I alluded to earlier in Section 2, part V, the qualitative nature of the results I present below is only dependent on the link between human capital and technological progress, although their quantitative nature-in particular the extended delay of the onslaught of the post-Malthusian era-depends on both population and human capital playing a role in technological progress.
} 


$$
\left\{n_{t}, e_{t+1}, s_{t}\right\}=\operatorname{argmax}\left\{\begin{array}{l}
\ln w_{t} h_{t}\left[1-n_{t}\left(\tau^{n}+\tau^{e} e_{t+1}\right)-s_{t}\right] \\
+\alpha p_{t+1} \ln s_{t} w_{t} h_{t}+\beta\left(1+p_{t+1}\right) \ln n_{t} \\
+(1-\beta)\left(1+p_{t+1}\right) \ln w_{t+1}\left(1+\phi_{t} e_{t+1}\right)
\end{array}\right\}
$$

subject to $\left(n_{t}, e_{t+1}, s_{t}\right) \geq 0$.

The first term in equation (8) corresponds to $\ln c_{t}^{t-1}$, the second to $\alpha p_{t+1} \ln c_{t+1}^{t-1}$, and the third and fourth to $\left(1+p_{t+1}\right)\left[\beta \ln n_{t}^{t-1}+(1-\beta) \ln I_{t+1}^{t}\right]$.

The first-order condition with respect to each of the arguments, $n_{t}, e_{t+1}, s_{t}$, are respectively given by the following:

$$
\begin{gathered}
\frac{\beta p_{t+1}}{n_{t}}-\frac{\tau^{n}+\tau^{e} e_{t+1}}{1-n_{t}\left(\tau^{n}+\tau^{e} e_{t+1}\right)-s_{t}} \leq 0 \\
\frac{(1-\beta) \phi_{t} p_{t+1}}{1+\phi_{t} e_{t+1}}-\frac{\tau^{e} n_{t}}{1-n_{t}\left(\tau^{n}+\tau^{e} e_{t+1}\right)-s_{t}} \leq 0 \\
\frac{\alpha p_{t+1}}{s_{t}}-\frac{1}{1-n_{t}\left(\tau^{n}+\tau^{e} e_{t+1}\right)-s_{t}} \leq 0
\end{gathered}
$$

Given the properties of the survival function, $p_{t+1}$, an interior solution will always exist for the optimal number of children, $n_{t}$, and the share of total income earmarked for second period consumption, $s_{t}$. That is not the case, however, with respect to optimal education, $e_{t+1}$. More specifically, there exists low enough values of the technology parameter, $A_{t}$, and of geographic characteristics, $G$, that the odds of survival are relatively low. For such values, the optimal amount of education per child equals zero. For other values, an interior solution exists for all control variables and we can determine the following utilizing (9):

$$
n_{t}\left(\tau^{n}+\tau^{e} e_{t+1}\right)=\frac{\beta\left(1+p_{t+1}\right)}{1+\beta+(\alpha+\beta) p_{t+1}}
$$




$$
\begin{gathered}
n_{t}=\frac{(2 \beta-1)\left(1+p_{t+1}\right)}{1+\beta+(\alpha+\beta) p_{t+1}} \frac{\phi_{t}}{\phi_{t} \tau^{n}-\tau^{e}}, \\
e_{t+1}=\frac{(1-\beta) \phi_{t} \tau^{n}-\beta \tau^{e}}{(2 \beta-1) \phi_{t} \tau^{e}},
\end{gathered}
$$

and,

$$
s_{t}=\frac{\alpha p_{t+1}}{1+\beta+(\alpha+\beta) p_{t+1}}
$$

Equations (10)-(13) illustrate the influence of both survival uncertainty and the returns to education on optimal choices:

Remark 1: (i) $\forall\left(n_{t}, e_{t+1}, s_{t}\right)>>0$ that satisfy (10)-(13), higher survival odds, $p_{t+1}$, raise $n_{t}$ and $s_{t}$,

$$
\frac{\partial n_{t}}{\partial p_{t+1}}, \quad \frac{\partial s_{t}}{\partial p_{t+1}} \quad>0
$$

(ii) $\forall\left(n_{t}, e_{t+1}, s_{t}\right)>>0$ that satisfy (10)-(13), higher returns to education, $\phi_{t}$, lower fertility, $n_{t}$, and raise average education, $e_{t+1}$;

$$
\frac{\partial n_{t}}{\partial \phi_{t}}<0, \quad \frac{\partial e_{t+1}}{\partial \phi_{t}}>0 .
$$

Noting that $p_{t+1}=p\left(I_{t}\right)=p\left(A_{t} G h_{t}\right)$ and $\phi_{t}=\phi\left(A_{t}\right)$, we identify that the sophistication of existing technologies affects optimal fertility through two channels. First, the "life-expectancy" effect: Because technological progress leads to higher incomes, it improves the likelihood that any given individual will survive to live three periods. As Remark 1 suggests, this manifests itself in a shift in the total amount of resources allocated to old-age enjoyment since both the saving rate, $s_{t}$, and the total amount of resources devoted to the upbringing of the offspring, $n_{t}\left(\tau^{n}+\tau^{e} e_{t+1}\right)$, rise. Second, the "education-premium" effect: A more sophisticated technology raises the return to education, and again due to Remark 1, this propagates the shift from quantity towards 
quality. Hence, while technological progress unambiguously raises the optimal education level of each offspring, it may increase, decrease, or even leave unchanged the optimal number of offspring depending on which of the above-mentioned effects dominates.

More specifically, net fertility rates will first rise and then fall over the course of economic development if the life-expectancy effect dominates in the early stages of development and the education-premium effect influences its later stages. ${ }^{23}$ In order to incorporate this idea into the model, consider

Assumption A.1: $\quad \lim _{A_{t} \rightarrow 0} \frac{p^{\prime}}{\phi^{\prime}}=\infty \quad$ and $\quad \lim _{A_{t} \rightarrow \infty} \frac{p^{\prime}}{\phi^{\prime}}=0$.

Assumption A.1 guarantees that improvements in the level of technology raise survival odds more than the education premium when the technology is relatively primitive. It also ensures vice versa when the technology is more sophisticated. Now let

$$
\Upsilon^{*} \equiv\left\{\left(A_{t}, e_{t}, g_{t} ; G\right) \mid p^{\prime} \geq \gamma \phi^{\prime}\right\}
$$

where $\gamma \equiv\left\{\left(1+p_{t+1}\right)\left[1+\beta+(\alpha+\beta)\left(1+p_{t+1}\right)\right] \tau^{e} \phi^{\prime}\right\} /\left\{(1+\beta) \phi_{t}\left(\phi_{t} \tau^{n}-\tau^{e}\right) p^{\prime}\right\}$. Then, Proposition 1 follows:

Proposition 1: $\forall A_{t} \geq 0$, technological progress (i) raises the fraction of income devoted to consumption during old age,

$$
\frac{\partial s_{t}}{\partial A_{t}}>0
$$

(ii) raises the optimal amount of education each offspring receives,

$$
\frac{\partial e_{t+1}}{\partial A_{t}}>0
$$

and under (A.1) (iii) leads to higher (lower) fertility in the early (late) stages of development,

\footnotetext{
${ }^{23}$ For empirical and theoretical relevance, see footnote 8 .
} 


$$
\frac{\partial n_{t}}{\partial A_{t}} \begin{cases}>0 & \text { iff }\left(A_{t}, e_{t}, g_{t} ; G\right) \in \Upsilon^{*} \\ \leq 0 & \text { iff }\left(A_{t}, e_{t}, g_{t} ; G\right) \notin \Upsilon^{*}\end{cases}
$$

Proof: See Appendix section 9.1.

In sum, the optimization problem specified by (8) implies the following: First, given the human capital accumulation process described by (6), there is no guarantee that the returns to education will warrant individuals to train their offspring. In fact, the first-order condition for $e_{t+1}$ in (9) suggests that there exists a set $\tilde{\Upsilon}$ such that, $\forall$ $\left(A_{t}, e_{t}, g_{t} ; G\right)>>0$,

$$
\tilde{\Upsilon} \equiv\left\{\left(A_{t}, e_{t}, g_{t} ; G\right) \mid(1-\beta) \phi\left(A_{t}\right) p_{t+1}-\tau^{e} n_{t} /\left(1-\tau^{n} n_{t}-s_{t}\right) \leq 0\right\}
$$

Thus, $\forall\left(A_{t}, e_{t}, g_{t} ; G\right) \in \tilde{\Upsilon}$, the combination of geography, technology and human capital is such that parents do not find it optimal to educate their young. Their struggle for survival dictates that all of their time and resources are devoted to having children and ensuring some old-age consumption. Put somewhat differently, when survival is relatively more difficult, individuals cut down on the consumption of the goods that they enjoy disproportionately more when they get old (which under this formulation is the quantity and the quality of their offspring and old-age consumption). Moreover, because individuals' resources are scarce, the number of offspring individuals have and the amount of resources they devote to old-age consumption are still relatively low.

$\forall\left(A_{t}, e_{t}, g_{t} ; G\right) \notin \tilde{\Upsilon}$, individuals educate their offspring as well. The amount of time they choose to devote to their offspring's education increases as the sophistication of existing technologies improves. And as long as $\left(A_{t}, e_{t}, g_{t} ; G\right) \in \Upsilon^{*}$, they also choose to have more children in response to technological change. In contrast if $\left(A_{t}, e_{t}, g_{t} ; G\right) \notin \Upsilon^{*}$, individuals have fewer but more educated children in response to technological progress.

Figure 1 shows how the optimal saving rate, $s_{t}$, number of children, $n_{t}$, and their average education levels, $e_{t+1}$, evolve as the technology, $A_{t}$, improves. While the optimal saving rate and the average education levels increase monotonically in $A_{t}$, the optimal number of offspring is a hump-shaped function of it. 
[Figure 1 about here.]

Before moving on to the dynamics, note that geography affects this economy both directly and indirectly. On the one hand, geographic characteristics directly influence the production process. Therefore, they help determine the productivity of labor. On the other hand, these characteristics affect labor income and labor income determines the odds of survival. And as we have identified above, the latter impacts household decisions regarding fertility, education and saving for old-age consumption. ${ }^{24}$

\section{The Dynamics}

There are two state variables in our economy: The level of technology, $A_{t}$, and the average education level of workers, $e_{t}$. At any given time $t$, technological sophistication alone determines the returns to education, $\phi_{t}$, and the two state variables-together with the economy's geographic characteristics, $G$-influence survival, $p_{t+1}$. The returns to education and survival odds, in turn, affect the optimal quantity and quality of children, $n_{t}$ and $e_{t+1}$, as well as saving for old-age consumption, $s_{t+1}$. The average education of workers then determines the rate of technological progress, $g_{t+1}$, and the sophistication of technologies in the future, $A_{t+1}$. Thus, the state variables evolve according to the following first-order difference equations:

$$
\begin{aligned}
A_{t+1} & =\left[1+g\left(e_{t}, L_{t}\right)\right] A_{t} \\
e_{t+1} & =e\left(A_{t}\right)
\end{aligned}
$$

The dynamic evolution of an economy will be driven by the historically and geographically given quadruplet $\left(A_{0}, e_{0}, g_{0} ; G\right)$. Given these initial conditions, the dynamic system will be in one of two possible regimes at any given time $t$. In this section, I first

\footnotetext{
${ }^{24}$ Another indirect channel through which geography could potentially manifest itself in the demographic makeup of regions is migration. Although the model here abstracts from the idea that geographic characteristics might influence migration flows, the incorporation of such an endogenous mechanism would serve to further propagate the indirect effects of geography on demographic and economic changes.
} 
informally discuss the two regimes and then more formally characterize the long-run equilibrium of the economy in Proposition 2.

(I) $\quad\left(A_{0}, e_{0}, g_{0} ; G\right) \in \tilde{\Upsilon}:$ One possibility is that the initial values of the two state variables, the rate of technological progress and geographic conditions, $\left(A_{0}, e_{0}, g_{0} ; G\right)$, do not lead to high enough survival odds initially, $p_{1}$. This is the case in which an economy is trapped in Malthusian stagnation. Survival is hard enough that a disproportionately large fraction of individuals' incomes are allocated to themselves rather than their offspring. Moreover, whatever time individuals choose to allocate to their young is only devoted to rearing them as the returns to education is low enough that parents choose not to educate their young at all. In this case, $\forall t>0, e_{t+1}=0 \Rightarrow g_{t+2}=g(0)=0$. As a result, technology remains primitive and life expectancy remains low. Fertility either sustains a very low population growth (which, for the most part, maintains a steady or slightly increasing population level) or leads to negative population growth (which lowers the level of population). Such an economy is then characterized by the following, $\forall t>$ 0 ,

$$
\begin{gathered}
A_{t+2}=A_{t+1}=A_{1}, \\
e_{t+1}=0, \quad h_{t+1}=1, \\
n_{t}=\bar{n}_{0} \equiv \frac{\beta}{\tau^{n}} \frac{1+p\left(A_{1} G\right)}{1+\beta+(\alpha+\beta) p\left(A_{1} G\right)} \lesseqgtr 1, \\
s_{t}=\bar{s}_{0} \equiv \frac{\alpha p\left(A_{1} G\right)}{1+\beta+(\alpha+\beta) p\left(A_{1} G\right)} .
\end{gathered}
$$

(II) $\quad\left(A_{0}, e_{0}, g_{0} ; G\right) \notin \tilde{\Upsilon}:$ The other possibility is that the initial values of the two state variables, the rate of technological progress and geographic conditions, $\left(A_{0}, e_{0}, g_{0}\right.$; $G$ ), allow for relatively high survival initially, $p_{1}$. Under this case, individuals expect to live longer. Consequently, they devote more of their resources to old-age consumption and the upbringing of offspring. Moreover, given that the returns to education are also relatively high, young adults also choose to educate their children. At first, when the size of the working population is relatively small so that $L_{t} \leq L^{*}$, the investment in the training of the young does not generate technological progress. However, as the size 
of the population gradually increases and reaches a sufficiently high level so that $L_{t}>$ $L^{*}$, an era of technological progress eventually ensues. As Proposition 1 suggests, this generates further increases in the fraction of time allocated to education. Thus under this scenario a steady state does not exist and the economy grows forever. The economy does not even reach a Balanced Growth Path (BGP) over a finite period of time, and only as $t \rightarrow \infty$ does it approach a BGP where technological progress, $g_{t+1}$, life expectancy, $\left(2+p_{t+1}\right)$, fertility, $n_{t}$, educational attainment, $e_{t+1}$, stabilize, and the level of technology, $A_{t}$, improves at a steady rate.

With respect to population growth, there are two sub-cases to consider under (II): If $\left(A_{0}, e_{0}, g_{0} ; G\right) \in \Upsilon^{*}$, technological progress initially leads to faster population growth. But as technological sophistication improves, the combination of technology, parental education and geographic characteristics becomes such that $\left(A_{t}, e_{t}, g_{t} ; G\right) \notin \Upsilon^{*}$ and population growth eventually declines. In contrast, if $\left(A_{0}, e_{0}, g_{0} ; G\right) \notin \Upsilon^{*}$, then population growth monotonically decreases as the level of technology improves. As $t \rightarrow$ $\infty$, an economy that starts out in regime (II) converges to the following BGP:

$$
\begin{gathered}
A_{t+1}=(1+\bar{g}) A_{t} ; \quad \bar{g} \equiv g(\bar{e}, \infty) \\
e_{t+1}=\bar{e}=\frac{1-\beta}{2 \beta-1} \frac{\tau^{n}}{\tau^{e}}>0, \quad h_{t+1}=\bar{h}=1+\bar{e} \\
n_{t}=\bar{n}_{1} \equiv \frac{(2 \beta-1)(1+\bar{p})}{1+\beta+(\alpha+\beta) \bar{p}} \frac{\bar{\phi}}{\bar{\phi} \tau^{n}-\tau^{e}} \lesseqgtr \bar{n}_{0} \\
s_{t}=\bar{s}_{1} \equiv \frac{\alpha \bar{p}}{1+\beta+(\alpha+\beta) \bar{p}}>\bar{s}_{0} .
\end{gathered}
$$

Proposition 2: (i) $\forall\left(A_{0}, e_{0}, g_{0} ; G\right) \in \tilde{\Upsilon}, \exists$ a unique steady state in which, $\forall t>0, h_{t+1}=1 \Leftrightarrow e_{t+1}=0 \Leftrightarrow g_{t+2}=0 \Leftrightarrow A_{t+2}=A_{t+1}, n_{t}=\bar{n}_{0}$, and $s_{t}$ $=\bar{s}_{0} . \forall t>0$, the economy remains in this Malthusian steady state. (ii) $\forall$ $\left(A_{0}, e_{0}, g_{0} ; G\right) \notin \tilde{\Upsilon}, \exists$ a unique balanced growth path (BGP) in which $h_{t+1}=$ $\bar{h}=1+\bar{e}, g_{t+2}=\bar{g}>0 \Leftrightarrow A_{t+2}=(1+\bar{g}) A_{t+1}, n_{t}=\bar{n}_{1} \lesseqgtr \bar{n}_{0}$, and $s_{t}=\bar{s}_{1}>$ $\bar{s}_{0} . \forall\left(A_{0}, e_{0}, g_{0} ; G\right) \notin \tilde{\Upsilon}$, the economy settles asymptotically on the balanced growth path (BGP) as $t \rightarrow \infty$. (iii) For any $\left(A_{0}, e_{0}, g_{0} ; G\right)$, the economy will either converge to the no-growth steady state in (i) or will continue to grow endogenously as described in (ii). 
Proof: See Appendix section 9.2.

Figure 2 depicts the long-run evolution of the state variables $A_{t}$ and $e_{t}$. The two equations in (16) completely characterize the dynamics of the economy. If $\left(A_{0}, e_{0}, g_{0}\right.$; $G) \notin \tilde{\Upsilon}$, the economy starts out in regime (II). And if $\left(A_{0}, e_{0}, g_{0} ; G\right) \in \tilde{\Upsilon}$, the economy begins in regime $(\mathrm{I})-$ or $(\mathrm{I}) \cup(\mathrm{I})^{\prime}$ if $G$ is smaller. For an economy in (I) or $(\mathrm{I}) \cup(\mathrm{I})^{\prime}$, $\forall t>0, A_{t}=A_{1}$ and $e_{t}=0$. For an economy that starts out in (II), the $E E$ locus, $E E \equiv e_{t+1}-e_{t}=0$, is upward sloping. However, the $A A$ locus, $A A \equiv A_{t+1}-A_{t}=0$, depends on whether population, $L_{t}$, exceeds $L^{*}$ or not (and consequently, whether the rate of technological progress, $g_{t+1}$, is strictly positive or zero). When $L_{t} \leq L^{*}$, the $A A$ locus covers the space (II) entirely. In that case, there are no dynamics (past the first period) until $L_{t}$ exceeds $L^{*}$. When $L_{t}>L^{*}$, however, the $A A$ locus lies on the $A_{t}=0$ line (the diagram only depicts the case when $L_{t}>L^{*}$ ).

The figure also illustrates the impact of a more advantageous geographic location on the long-run evolution of the economy. In essence, a higher $G$ contracts the set to (I) from that given by $(\mathrm{I}) \cup(\mathrm{I})^{\prime}$, and makes it more likely that the economy will initially be in regime (II).

[Figure 2 about here.]

As Proposition 1 makes clear, economies that start out with identically primitive technologies and little or no human capital still evolve differently over time to the extent that their geographic characteristics differ. Even in regions where geographic conditions are favorable to an eventual economic and demographic takeoff from the Malthusian regime, however, the transition process may take long. The reason for this is that the rate of technological progress, which depends on the stock of education and population size, is zero initially. But steady population growth and investment in education combine to eventually trigger a process of technological change. This in turn raises the return to education and geographically favorable economies enter the post-Malthusian phase during which fertility and educational attainment increase and life expectancy improves. 


\section{From Geography to Institutions}

The model above ascribes a very important role to geographic characteristics in triggering the modern demographic transition and generating the human capital accumulation necessary for sustained technological progress. And the model presented so far best describes the very long-run evolution of economies that have no outside access to superior technologies-either because their existing technology is already at the world frontier or because their institutional arrangements do not favor technology transfers. But what if an underdeveloped economy can import and adopt sophisticated technologies? After all, an advanced technology can make up for the negative impact of an adverse geography in the sense that, for any $G$, there exists a level of technology $A_{t}$ such that $\left(A_{t}\right.$, $\left.e_{t}, g_{t} ; G\right) \notin \tilde{\Upsilon}{ }^{25}$ This would put any economy on the path of demographic transition and economic prosperity once technologies improve enough. Hence, while geography and natural resources are important in understanding the origins of economic development and demographic transition, they may have a minor and diminishing role in explaining the varying paths taken by the less developed countries since the European Industrial Revolution. In fact, in a world where the technology frontier is relatively more advanced institutions will become more important. The reason is that, if countries' legal, financial and political institutions help to promote technology transfers and adoption, then all economies would have a combination $\left(A_{t}, e_{t}, g_{t} ; G\right) \notin \tilde{\Upsilon}$ at some point. ${ }^{26}$ And the process of demographic transition and economic development would eventually kick start despite a country's geography.

Cross-country differences in geography introduce the possibility of multiple equilibria in this model. And economies' prospects diverge mostly due to the indirect impact of geography on households' economic and demographic decisions. It is important to note, however, that geographic characteristics also directly influence production. Thus,

\footnotetext{
${ }^{25}$ McNeill (1998, pp. 46-47) explains how this mechanism was at work even during ancient times when he notes, "Never before had a dominant, large-bodied species been able to spread all around the globe. Humans could accomo date this feat because they learned how to create micro-environments suitable to the survival of a tropical creature under widely varying [ecological] conditions. Invention of different sorts of clothing did the trick, insulating the human body from extremes of climate and assuring survival despite freezing temperatures."

${ }^{26}$ For the purposes of this discussion, I employ a narrow and admittedly loose definition of what institutions entail by focusing only on their role in allowing cross-sountry technology transfers and adoption. Nonetheless, to the extent that the creation and emergence of institutions that secure property rights that foster productive activities are a by-product of the human capital accumulation process (as discussed on page 12), the cross-country transfer and adoption of these more broadly defined institutions of private property become more relevant.
} 
while the creation of institutions that promote technology transfer and adoption can eliminate the multiplicity of equilibria, they will not be sufficient to offset the direct geography effect. Nonetheless, small differences in geographic characteristics can lead to highly divergent paths of economic progress due to the indirect geography effect, which progress-friendly institutions will help to eliminate.

\section{Numerical Examples}

In this section I provide a computational analysis to highlight some of the main conclusions. The simulations discussed here are intended to be suggestive and are not designed to capture precisely all of the quantitative aspects of human progress. Nonetheless, they help to illustrate that initial differences in geographic endowments go a long way in generating the empirically consistent patterns of demographic change, technological progress and economic development.

I simulate the above-described economy for roughly 5,000 years. This corresponds to 200 model periods based on a generation gap of about 25 years. In order to carry out the simulations, I first assign specific functional forms to how survival odds, $p_{t+1}$, are related to income, $I_{t}$-the generalized version of which was introduced in equation (3)-and the explicit relationship between the average education level of the economy, $e_{t}$, and the subsequent rate of technological progress, $g_{t+1}$, described in (7). Thus,

$$
p_{t+1}=\frac{I_{t}^{\gamma}}{\lambda+I_{t}^{\gamma}} ; \quad \gamma, \lambda>0
$$

and

$$
g_{t+1}=\left\{\begin{array}{l}
0 \\
\theta e_{t}^{\delta}\left(L_{t}-L^{*}\right)^{\eta} ;
\end{array} \quad \theta>0, \quad 1>\delta, \eta>0,\right.
$$

where (19) satisfies the properties discussed on page 10, and (20) those presented after equation (7). And to specify the effect of the level of technology on the education premium, I assume 


$$
\phi_{t}=\left(\psi+A_{t}\right)^{v} \quad \psi>0,1>v>0 .
$$

In (21), $\psi>0$ ensures that (A.1) is satisfied. I then parameterize the model and assign initial values to the state variables, $A_{t}$, and $e_{t}$. There are 13 variables and 3 initial values (two for the state variables $A_{0}$ and $e_{0}$, one for the pseudo-state variable $L_{0}$ ) that need to be parameterized. I simulate the economy for five different sets of parameter specifications. Table 1 presents my parameter choices.

[Table 1 about here.]

In all simulations, I set most parameter values-such as those in equations (19)(21)-at their chosen values for convenience. Given that I am modeling the very long run evolution of human kind, I also choose the initial average education level, $e_{0}$, to be zero and the initial level of the technology, $A_{0}$, to be a small positive value.

The first simulation, for which the evolutions of population, saving rate, fertility, and education are provided in Figure 3, compares two economies that differ in their geographic endowments by 40 percent. $^{27}$ In the figure, $G$ equals 1.0 for the economy shown by the solid line, and it equals 0.60 for the other shown by the dashed line. Under these parameter specifications, economy (a) is in regime (II) where it is set for an eventual takeoff, and economy (b) is in regime (I) where it can never escape the Malthusian trap. As the simulation results show, even for economy (a) it takes about 170 model periods (or approximately 4,300 years) for the economy to undergo the transition from the Malthusian world to the modern one. Once that transition begins, the quickening pace of technological progress leads to an increase and then a decrease in population growth, and life expectancy and the average education level increase rapidly as the demographic transition phase starts to unfold. What is also interesting in this simulation is that the geographic endowment of economy (b) is not even abundant enough to sustain a

\footnotetext{
${ }^{27}$ Columns (a) and (b) of Table 1 provide a comparison of these two economies.
} 
growing or even a stable population. In fact, within 10 generations the economy's working population reaches roughly one-tenth of its initial level of 10,000.

The second simulation, for which results are depicted in Figure 4, shows a comparison of economy (a) with another that eventually undergoes demographic transition. Hence, both economies begin in regime (II). The only difference between them is that their geographic characteristics differ only by 10 percent. ${ }^{28}$ In the figure, $G$ equals 1 for the economy shown by the solid line, and it equals 1.1 for the other shown by the dashed line. This simulation illustrates how large the impact of geographic characteristics can be on delaying the shift from the Malthusian world to the post-Malthusian regime, and eventually from that to the modern transition era. Economy (a), for which $G$ equals 1 , enters the post-Malthusian era roughly 15 model periods or four centuries later than economy (c), for which $G$ equals 1.1 .

[Figures 3 and 4 about here.]

The third simulation calibrates the model to match the historic population dynamics of Western Europe. ${ }^{29}$ The parameter values for this simulation, which were chosen to match the implied population dynamics as close as possible, are listed in Table 1, column (d). The results are shown in Figure 5. The first panel presents the levels of population predicted by the model (shown by the solid line) as well as the estimates constructed based on Maddison (shown by the dashed line) and Russell (shown by the dotted line). The following three panels respectively show the fertility rate, the mortality rate and

\footnotetext{
${ }^{28}$ Column (c) of Table 1 provides the parameter specifications for this new economy.

${ }^{29}$ For the purposes of this exercise, Western European countries include Austria, the British Isles, Finland, France, Germany, Greece, Italy, Norway, Portugal, Spain, and Sweden. I rely on a variety of sources to construct the population data: Russell (1972) provides estimates for Medieval Europe between 500 A.D. and 1450 A.D. and Maddison (2001) constructs Western European population estimates as far back as year zero. Utilizing these and the population growth rates computed by Kremer (1993), Jones (1999), and Weil (2001), I extrapolate Western European population for the earlier years for which estimates do not exist. Table 2.a provides the data put together by Russell and Maddison as well as the world population growth rates between 3000 B.C. and 1998 calculated by Jones (2001). Table 2.b presents the population series that I have constructed relying on estimates by Maddison, Russell and Jones (1999).
} 
the net population growth rate. In general, the model matches the historical Western European population trend rather nicely. It does, however, overshoot the level of the population for a number of periods-just like in Jones (2001)-and under-predicts it for the last century. As can be seen by the drop in actual population around the early 15th century, one reason for the model to overshoot the actual level of European population until the very final periods is the dramatic rise in mortality and the associated decline in population in the late 14 th century due to Black Death.

In the final simulation I replicate the above exercise for Africa. ${ }^{30}$ The parameter values for this simulation are listed in the final column of Table 1 . They are identical to the ones selected for the Western European simulation with the exception that $G$ now equals 0.75 instead of 1 . The results are shown in Figure 6. There are two somewhat surprising results: One, with $G$ equals 0.75 , the fit of the model with actual population dynamics is extremely well until the last three or four model periods. And two, even with $G$ equals 1 (for which the population dynamics are depicted by the dashed line in the top panel), the model falls well short of explaining the African population boom witnessed during the 20th century. One can attribute at least part of this growth to the introduction of better health care by European colonial settlers and missionaries in the late-19th and early-20th centuries. ${ }^{31}$ In fact, the rates of population growth in lessdeveloped countries are still far higher than those experienced during the aftermath of the Industrial Revolution, suggesting that the adoption of more sophisticated technologiesat least in health care-might have begun to dilute the role of geography in development and demography.

[Figures 5 and 6 about here.]

\footnotetext{
${ }^{30}$ The methodology that I employ is idenitcal to the one above except for the fact that population estimates are now based on Maddison (2001) and Biraben. See Tables 3.a and 3.b for the underlying data and my estimates.

${ }^{31}$ Most of the improvement in health care was simply attributed to a separation of clean water and waste water. Atack and Passell (1994) discuss the extent to which filtering the water supply, which began in the United States during the 19th century, can lead to improvements in public health.
} 


\section{Implications and Further Discussion}

The model laid out above has a number of specific implications, some of which I have already discussed. In this section, I highlight some of the major ones more formally and present the supporting evidence that are relevant to each.

I) Geographic characteristics help to explain differences in early development as well as those in long-term demographic trends. One novel implication of the model presented here is that favorable geographic characteristics will be sufficient to kick start a demographic transition that is commensurate with the very long experience of human kind. Another is the notion that the geography of a region will manifest itself in the development of economies that inhabit a given location. McNeill (1998, p. 67) stresses this notion most clearly when he notes, "[Climate], more than anything else, is why Africa remained backward in the development of civilization when compared to temperate lands (or tropical zones like those of the Americas), where prevailing ecosystems were less elaborated and correspondingly less inimical to simplification by human action. Ecosystems in the regions of the earth where early and historically important agricultural societies first developed were all intrinsically less resistant to human alteration than in tropical Africa." What needs to be emphasized in this context is the inextricable link between economic performance and demographic change-the theoretical precursors of which were initially laid out in Becker, Murphy, and Tamura, Galor and Weil (1996, 1998), and Jones (2001). This link would suggest geography as an important factor that affects the joint evolution of technological progress, early development, and demographic transition.

The model above specifically suggests that favorable geographic characteristics should lead to higher population densities, most certainly in the early phases of development. Table 4 and Figure 7 show the results of a test of this prediction using 1,500 A.D. population density data for Western Europe and its colonial offshoots. ${ }^{32}$ I confine at-

\footnotetext{
${ }^{32}$ The geography data are solely from Parker (1997). For each country they include latitude, $L A T I T U D E_{j}$, normalized measures of average annual temperature, $T E M P_{j}$, average morning humidity, $H U M I D_{j}$, cumulative total share of world mineral resources, $M I N E R A L_{j}$, and a dummy for whether the country is landlocked, $L L O C K_{j}$. The population density data, with the exception of those for Western Europe, are borrowed from Acemoglu et al. (2001) who in turn derive them from data provided by McEvedy and Jones (1978). Those for Western Europe are derived from McEvedy and Jones and the CIA World Fact Book. In addition to aggregated data for Western Europe, the sample includes 41 observations for Argentina, Algeria, Australia, Bangladesh, Belize, Bolivia, Brazil, Canada, Chile, Colombia, Cost Rica, Dominican Republic, Ecuador, Egypt, El Salvador, Guatamala, Guyana, Hong Kong, Honduras, Haiti, Indonesia, India, Jamaica, Laos, Sri Lanka, Morocco, Mexico, Malaysia, Nicaragua, New Zealand, Pakistan, Panama, Peru, the Philippines, Paraguay, Singapore, Tunisia, Uruguay, the United States, Venezuela, and Vietnam.
} 
tention to this subset because, together with Western Europe, it comprises countries for which Acemoglu et al. (2001) demonstrate that institutions-but not geography-played a role in their economic development since the 19th century. Columns (1)-(3) show the results from the OLS specifications, and (4)-(6) those from robust regressions that correct for outlier biases. As shown in the table, there is a statistically significant relationship between population density in 1,500 A. D. and humidity under all specifications, between temperature and population density under (5) and (6), and between population density and latitude under (4). Figure 7 isolates the effect of humidity as specified in (3) and illustrates its impact on population density. In general, these results support the idea that geographic characteristics might have been important in early development.

II) Technological breakthroughs and the creation of progress-friendly institutions are most likely to occur in economies with favorable geographies. Diamond extensively discusses why early civilizations first surfaced in the Fertile Crescent in the Mesopotamian peninsula, Mesoamerica, and China. He also provides a compelling reason for why the Industrial Revolution and its accompaniment of modern demographic change occurred on the Eurasian continent: While all the former were regions where the climate was mild and the natural supply of domesticable plant and animal species were relatively more abundant, the Eurasian continent was the only one where the major axis of orientation is east-west. This was a significant geographic benefit as "Eurasia's east-west axis allowed the Fertile Crescent crops quickly to launch agriculture over the band of temperate latitudes from Ireland to the Indus Valley."

In addition, if one were to adopt a broader interpretation of the state variable $A_{t}$ where it covers the institutional characteristics of an economy, the model above would also suggest that the establishment of institutions that promote economic progress first occurs in geographically favorable regions.

III) Demographic transitions will first occur in geographically advantageous regions. To the extent that technologies are transferable, they may subsequently occur elsewhere. In this model, multiple equilibria may occur as the initial levels of average education and technology, combined with the geographical characteristics of an economy, will determine whether an economy is trapped in a Malthusian state or it can eventually take off to undergo demographic change and economic development. Thus, a clear implication is that the demographic transition from the Malthusian state to the modern regime as well as the potential technological revolutions will first take place in, ceteris paribus, 
geographically favorable areas. This, of course, is the case. As just noted in (II), not only did the Industrial Revolution take place in Europe but also many of the more advanced civilizations emerged in geographically advantageous areas throughout the course of history. In addition, once the phase of post-Malthusian population growth started to take place in such regions, population densities rose sharply and relatively more in places where the climate was favorable and resources were abundant. ${ }^{33}$

When the pace of technological progress picks up somewhere, the world technology frontier starts to expand. Therefore, a relevant issue is whether economies located in geographically adverse regions can benefit from these technological improvements to eventually escape their trap. On the one hand, if technologies were fully transferable, it is clear that all economies-regardless of the extent to which their geographies are unfavorable-would eventually emerge from the Malthusian trap. On the other hand, the degree to which technologies are transferable across economies is questionable. ${ }^{34}$ Moreover, there exists work in the literature that suggests that the design and evolution of institutions that foster economic growth and development might historically have been driven by geographic characteristics. ${ }^{35}$

IV) Institutions that foster technology transfers and adoption will render the role of geography in development and demography mostly obsolete. If countries' legal, financial and political institutions help to promote technology transfers, then all economies would eventually have a combination $\left(A_{0}, e_{0}, g_{0} ; G\right) \notin \tilde{\Upsilon}$, and the process of demographic transition and economic development would kick start. Thus, the availability of relatively sophisticated technologies for import would imply that, while geographical characteristics might have affected the evolution of humankind early on, they do not help to describe how less-developed economies began to evolve after the European Industrial Revolution. Nor would they help to provide a description of how today's less-developed countries may evolve in the future. Of course, the extent to which technologies are not transferable and the existence of institutional features that hinder technology transfers will ultimately determine whether geography remains important. The empirical evidence provided by Hall and Jones, Gallup, Sachs and Mellinger suggests that geography con-

\footnotetext{
${ }^{33} \mathrm{An}$ illuminating example of how human populations start to grow in the presence of resource abundance is discussed in Weil (Ch. 4, p. 4). For more details, also see Larsen and Vaupel (1993) and Livvi-Bacci.

${ }^{34}$ Basu and Weil (1998).

${ }^{35}$ See Acemoglu, Johnson, and Robinson (forthcoming).
} 
tinues to help explain the cross-country patterns of economic growth and development. Acemoglu, Johnson and Robinson (2001) claim however that, while geography might have been important historically, institutional characteristics most significantly account for the contemporary differences in growth and development.

\section{Conclusion}

During most of its history, humankind struggled for survival. This struggle was all the more brutal where nature was not relatively cooperative. To what extent did the fate of human societies depend on nature? More importantly, can differences in geographic conditions help to explain the very long-run economic and demographic evolution of human societies?

In this paper, I argue that they can. I present a unified economic growth theory that focuses on geography in the very long run. The model links demographic transition to geography and shows that geography affects the economy mostly indirectly via its impact on economic decisions and demographics. The reason is that, by affecting the odds of survival, geographic characteristics influence household decisions-including those about the quantity and quality of children. And the latter in turn determine whether economies eventually attain the scale and scope necessary for sustained technological progress.

This link is made all the more relevant given the recent debate about the role of geography versus that of institutions in economic progress. While this debate revolves primarily around whether geographical characteristics or institutions account for the contemporary cross-country differences in economic prosperity, there is a growing body of evidence to shed doubt on a direct geography effect. At the same time, however, most findings are consistent with the view that geographic characteristics were important in the emergence of agriculture and early development. A novel aspect of the model presented here is the incorporation of direct and indirect channels through which geography could potentially impact economic prosperity. It is this aspect of the model that demonstrates how geography might have affected development in the early stages and why it may matter less today. 


\section{Appendix}

- 9.1. Proof of Proposition 1:

(i) Using (13) we find that

$$
\frac{\partial s_{t}}{\partial A_{t}}=\frac{\partial s_{t}}{\partial p_{t+1}} \frac{\partial p_{t+1}}{\partial A_{t}}=\frac{\alpha(1+\beta) p^{\prime}}{\left[1+\beta+(\alpha+\beta) p_{t+1}\right]^{2}}>0
$$

(ii) Using (12) we can establish that

$$
\frac{\partial e_{t+1}}{\partial A_{t}}=\frac{\partial e_{t+1}}{\partial \phi_{t}} \frac{\partial \phi_{t}}{\partial A_{t}}=\frac{\phi^{\prime}}{(2 \beta-1) \phi_{t}^{2}}>0 ;
$$

(iii) Finally, given (11) we find that

$$
\frac{\partial n_{t}}{\partial A_{t}}=\frac{\partial n_{t}}{\partial p_{t+1}} \frac{\partial p_{t+1}}{\partial A_{t}}+\frac{\partial n_{t}}{\partial \phi_{t}}=\frac{(2 \beta-1) \Pi}{\left[1+\beta+(\alpha+\beta) p_{t+1}\right]^{2}\left[\phi_{t} \tau^{n}-\tau^{e}\right]^{2}}
$$

where $\Pi=\left\{(1+\beta) \phi_{t}\left(\phi_{t} \tau^{n}-\tau^{e}\right) p^{\prime}-\left(1+p_{t+1}\right)\left[1+\beta+(\alpha+\beta)\left(1+p_{t+1}\right)\right] \tau^{e} \phi^{\prime}\right\}$. Un$\operatorname{der}$ (A.1), $\lim _{A_{t} \rightarrow 0}\left(p^{\prime} / \phi^{\prime}\right)=\infty$, and $\lim _{A_{t} \rightarrow \infty}\left(p^{\prime} / \phi^{\prime}\right)=0$. Moreover, $\Pi>0$ iff $\left(A_{t}, e_{t}, g_{t} ; G\right) \in \Upsilon^{*}$, and $\Pi<0$ iff $\left(A_{t}, e_{t}, g_{t} ; G\right) \notin \Upsilon^{*}$. Thus, $\forall\left(A_{t}, e_{t}, g_{t} ; G\right) \in \Upsilon^{*}$, $\partial n_{t} / \partial A_{t}>0$, and $\forall\left(A_{t}, e_{t}, g_{t} ; G\right) \notin \Upsilon^{*}, \partial n_{t} / \partial A_{t} \leq 0$.

- 9.2. Proof of Proposition 2: (i) If $\left(A_{0}, e_{0}, g_{0} ; G\right) \in \tilde{\Upsilon}$, then $e_{1}=0 \Rightarrow h_{1}=1 \Rightarrow$ $g_{2}=g(0)=0 \Rightarrow A_{2}=A_{1}$. Thus, $\forall t \geq 1, e_{t}=0, g_{t+1}=0$, and $A_{t+1}=A_{t}$. As a 
result, $\forall t \geq 1, n_{t}=\bar{n}_{0}$, and $s_{t}=\bar{s}_{0}$; (ii) If $\left(A_{0}, e_{0}, g_{0} ; G\right) \notin \tilde{\Upsilon}$, then $e_{1}>0 \Rightarrow$ $h_{1}>1 \Rightarrow g_{2}=g\left(e_{1}\right)>0 \Rightarrow A_{2}=\left(1+g_{2}\right) A_{1}>A_{1}$. Thus, $\forall t \geq 1, e_{t}>0, g_{t+1}$ $>0$, and $A_{t+1}>A_{t}$. And given that, $\forall t \geq 1, A_{t+1}>A_{t}$, the economy continues to evolve. In the limit as $t \rightarrow \infty, A_{t+1} \rightarrow \infty, p_{t+1} \rightarrow \bar{p}$, and as implied by (12), $e_{t+1} \rightarrow \bar{e}$. Moreover, $s_{t} \rightarrow \bar{s}_{1}$, which due to Proposition 1 , is strictly greater than $\bar{s}_{0}$. And, $n_{t} \rightarrow \bar{n}_{1}$, which due to Proposition 2 , may be less than, greater than or equal to $\bar{n}_{0}$; (iii) Proof follows directly from the fact that both regimes (I) and (II) are ergodic. 


\section{References}

Acemoglu, D. (1998). "Why Do New Technologies Complement Skills? Directed Technical Change and Wage Inequality," Quarterly Journal of Economics, 113(4), 1055-89.

Acemoglu, D., S. Johnson, and J. Robinson. (forthcoming). "The Colonial Origins of Comparative Development: An Empirical Investigation," American Economic Review.

Acemoglu, D., S. Johnson, and J. Robinson. (2001). "Reversal of Fortune: Geography and Institutions in the Making of the Modern World Income Distribution," MIT, unpublished manuscript.

Atack, J. and P. Passell. (1994). A New Economic View of American History from Colonial Times to 1940, (New York: W. W. Norton \& Company).

Bartel A. P. and F. R. Lichtenberg. (1987). "The Comparative Advantage of Educated Workers in Implementing New Technologies," Review of Economics and Statistics, 69 (1), February, 1-11.

Bartel A. P. and F. R. Lichtenberg. (1991). "The Age of Technology and Its Impact on Employee Wages," Economic Innovation: New Technology, 1 (3), 215-31.

Bartel A. P. and N. Sicherman. (1999). "Technological Change and Wages: An Interindustry Analysis," Journal of Political Economy, 107 (2), April, 285-325.

Basu, S. and D. N. Weil. (1998). "Appropriate Technology and Growth," Quarterly Journal of Economics, 113 (4), November, 1025-1054.

Becker, G. S. (1981). A Treatise on the Family, (MA: Harvard University Press).

Becker, G. S., K. M. Murphy, and R. Tamura. (1990). "Human Capital, Fertility, and Economic Growth," Journal of Political Economy, 98, October, S12-S37.

Diamond, J. (1998). Guns, Germs, and Steel: The Fates of Human Societies, (New York: W. W. Norton \& Co.).

Dollar, D. and A. Kraay. (2001). "Growth is Good for the Poor," World Bank Working Paper No.: 2587.

Fuchs, V. and D. Reklis. (1994). "Mathematical Achievement in Eighth Grade: 
Interstate and Racial Differences," NBER Working Paper No.: 4784.

Gallup, J. L., J. D. Sachs, and A. D. Mellinger. (1999). "Geography and Economic Development," Harvard Institute for International Development, CAER II Discussion Paper No: 39, March.

Galor, O. and D. N. Weil. (1996). "The Gender Gap, Fertility, and Growth," American Economic Review, 86 (3), June, 374-87.

Galor, O. and O. Moav. (1999). "From Physical to Human Capital Accumulation: Inequality in the Process of Development," Brown University Working Paper No: 199927, July.

Galor, O. and O. Moav. (2000). "Natural Selection and the Origin of economic Growth," Brown University Working Paper No: 2000-18, September.

Galor, O. and D. N. Weil. (2000). "Population, Technology and Growth: From the Malthusian Regime to the Demographic Transition," American Economic Review, 90 (4), September, 806-28.

Goldin, C. and L. F. Katz. (1998). "The Origins of Technology-Skill Complementarity," Quarterly Journal of Economics, 113, June, 683-732.

Grossman. H. I. and J. Mendoza. (2000). "Scarcity and Conflict," Brown University Working Paper No: 1999-19.

Hall, R. E. and C. I. Jones. (1999). "Why Do Some Countries Produce So Much More Output Per Worker Than Others?," Quarterly Journal of Economics, 114, February, 83-116.

Hansen, G. and E. Prescott. (2000). "From Malthus to Solow," University of Minnesota, unpublished manuscript.

Iyigun, M. F. (2000). "Timing of Childbearing and Economic Growth," Journal of Development Economics, 61 (1), February, 257-71.

Jones, E. L. (1981). The European Miracle, (Cambridge: Cambridge University Press).

Jones, C. I. (2001). "Was an Industrial Revolution Inevitable? Economic Growth over the Very Long Run," B.E. Journal in Macroeconomics, Advances in Macroeconomics, 
August 2001, Vol. 1, No. 2, Article 1.

Juhn, C., K. M. Murphy and B. Pierce. (1993). "Wage Inequality and the Rise in Returns to Skill," Journal of Political Economy, 101 (3), June, 410-42.

Kremer, M. (1993). "Population Growth and Technological Change: 1 Million B.C. to 1990," Quarterly Journal of Economics, 108(3), 681-716.

Landes, D. S. (1998). The Wealth and Poverty of Nations: Why Some are Rich and Some So Poor, (New York: W. W. Norton).

Larsen, U. and J. W. Vaupel. (1993). "Hutterite Fecundability by Age and Parity: Strategies for Frailty Modeling of Event Histories," Demography, 30(1), February, 81-102.

Livi-Bacci, M. (1997). A Concise History of World Population, (Oxford: Blackwell Publishers).

Maddison, A. (1982). Phases of Capitalist Development, (Oxford: Oxford University Press).

Maddison, A. (2001). The World Economy: A Millennial Perspective, Development Center Studies, OECD, June, vol. 1, no. 6.

Masters, W. A. and M. S. McMillan. (2001). "Climate and Scale in Economic Growth," Journal of Economic Growth, 6 (3), September, 167-86.

McEvedy C. and R. Jones. (1978). Atlas of World Population History, Facts on File, New York.

McNeill, W. (1998). Plagues and Peoples, (New York: Anchor Books/Doubleday).

Mokyr, J. (1990). The Lever of Riches, (New York: Oxford University Press).

Nelson, R. R. and E. S. Phelps. (1966). "Investment in Humans, Technological Diffusion, and Economic Growth," American Economic Review, 56 (2), May, 69-75.

Parker, P. M. (1997). National Cultures of the World: A Statistical Reference, (Connecticut: Greenwood Press).

Romer, P. (1990). "Endogenous Technological Change," Journal of Political Economy, 
98, October, S71-S102.

Rosenberg, N. and L. E. Birdzell, Jr. (1986). How the West Grew Rich. (New York: Basic Books).

Russell, J. C. (1972). "Population in Europe," in C. M. Cipolla ed., The Fontana Economic History of Europe, Vol. 1: The Middle Ages, (Glasgow: Collins/Fontana).

Sachs, J. D. (2000). "Notes on a New Sociology of Economic Development," in Culture Matters: How Values Shape Human Progress, L. E. Harrison and S. P. Huntington (eds.), (New York: Basic Books).

Sachs, J. D. (2001). "Tropical Underdevelopment," NBER Working Paper No: 8119, February.

Schultz, T. W. (1975). "The Value of the Ability to Deal with Disequilibria," Journal of Economic Literature, 13 (3), 827-46.

Weil, D. N. (2001). Economic Growth, manuscript, Brown University.

Wrigley, E. A. and R. S. Schofield. (1989). The Population History of England, 1541-1871: A Reconstruction, (Cambridge: Cambridge University Press). 
Figure 1: The evolutions of saving rate, population growth, and education

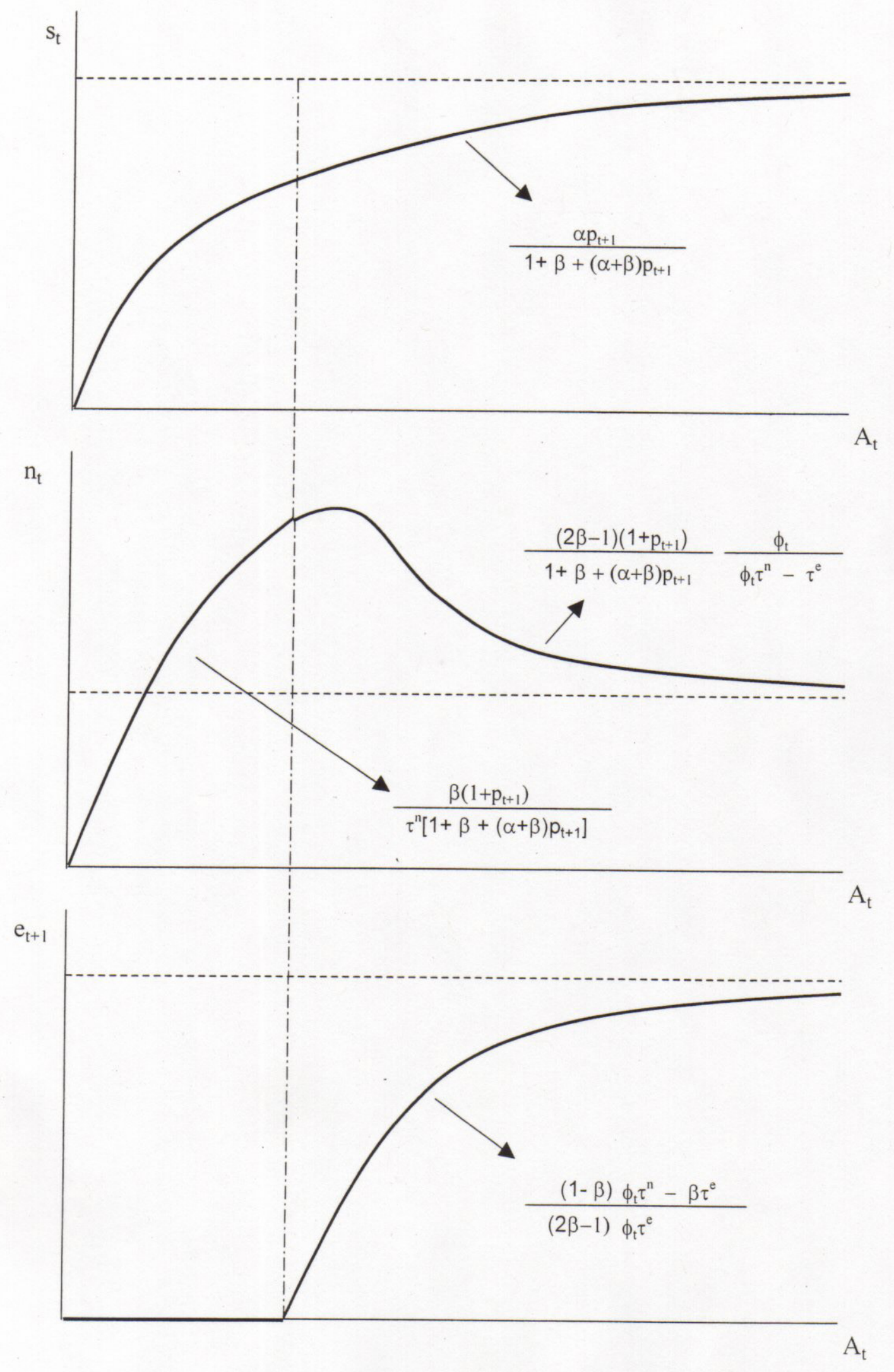


Figure 2: $\quad$ The Phase Diagram $\left(\mathrm{L}_{\mathrm{t}}>\mathrm{L}^{*}\right)$

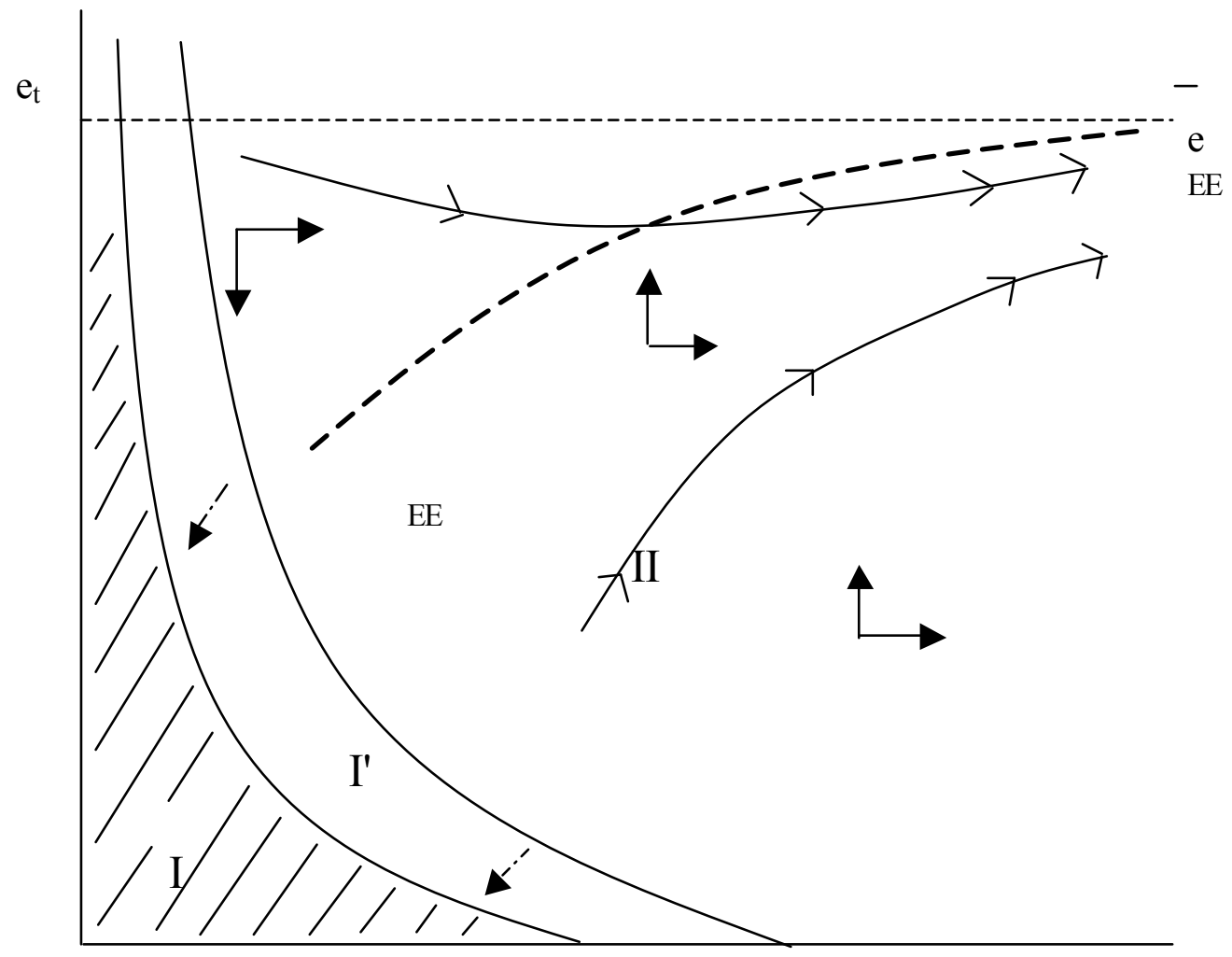

$\mathrm{A}_{\mathrm{t}}$ 


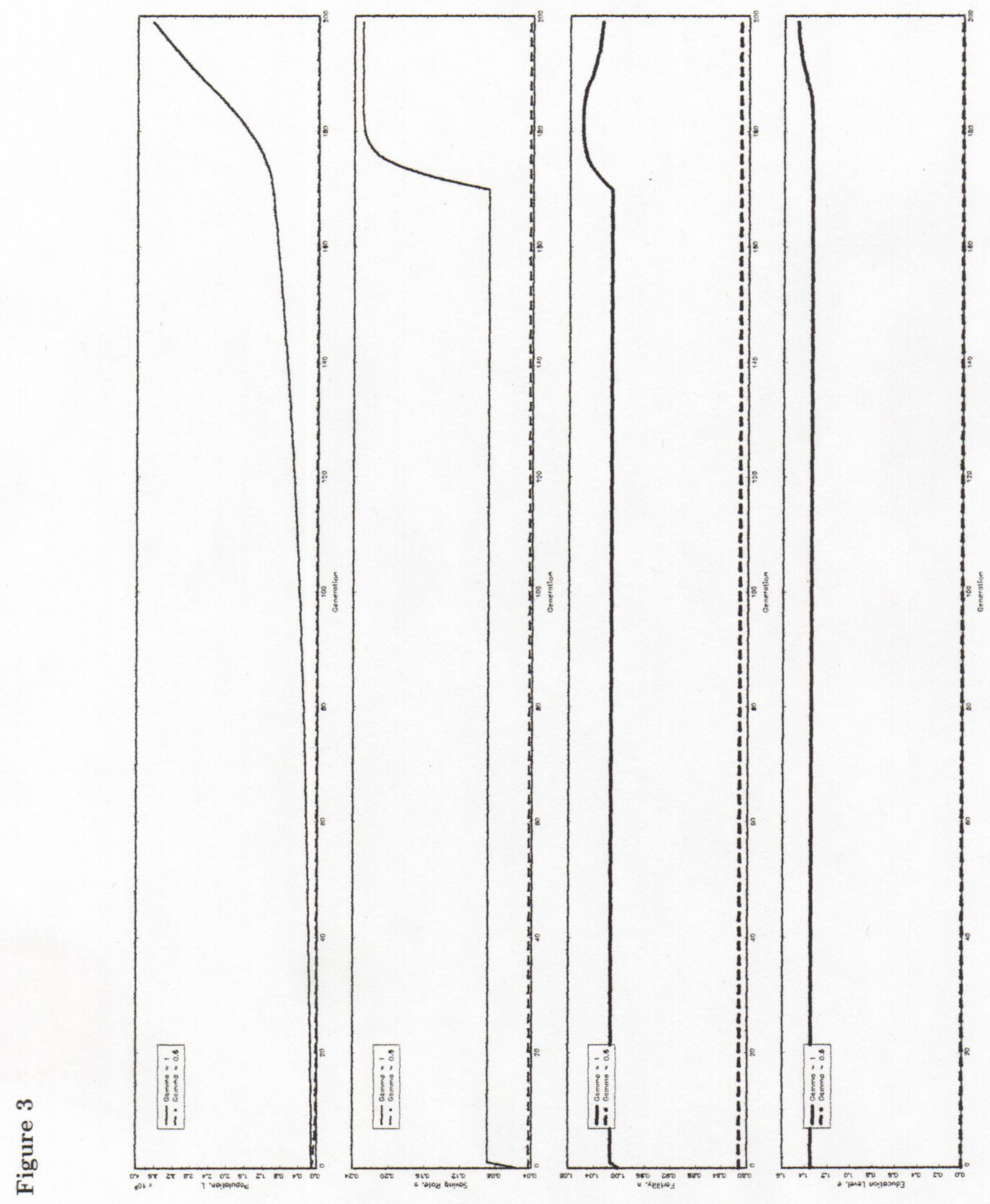

$\infty$ 

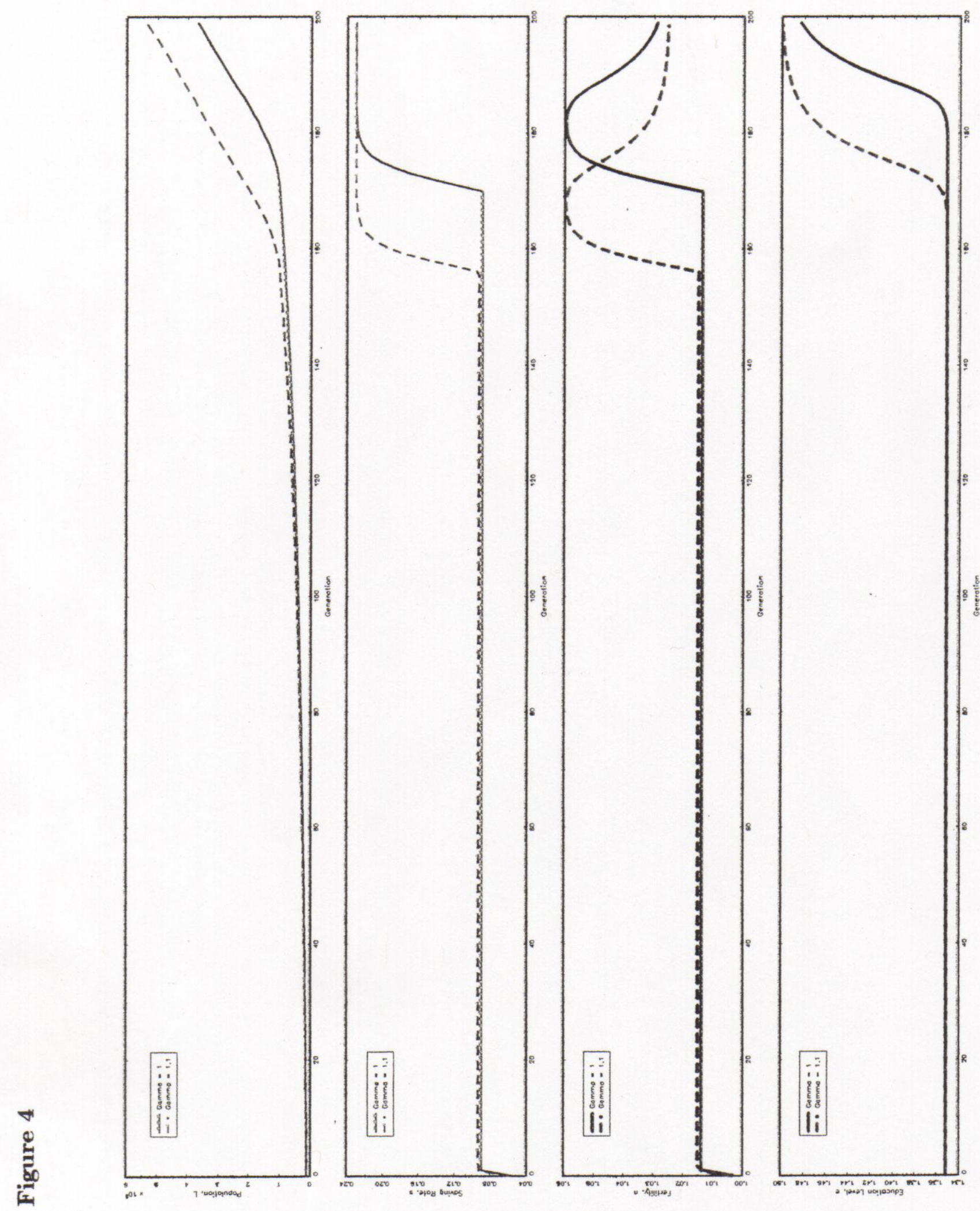

อ 


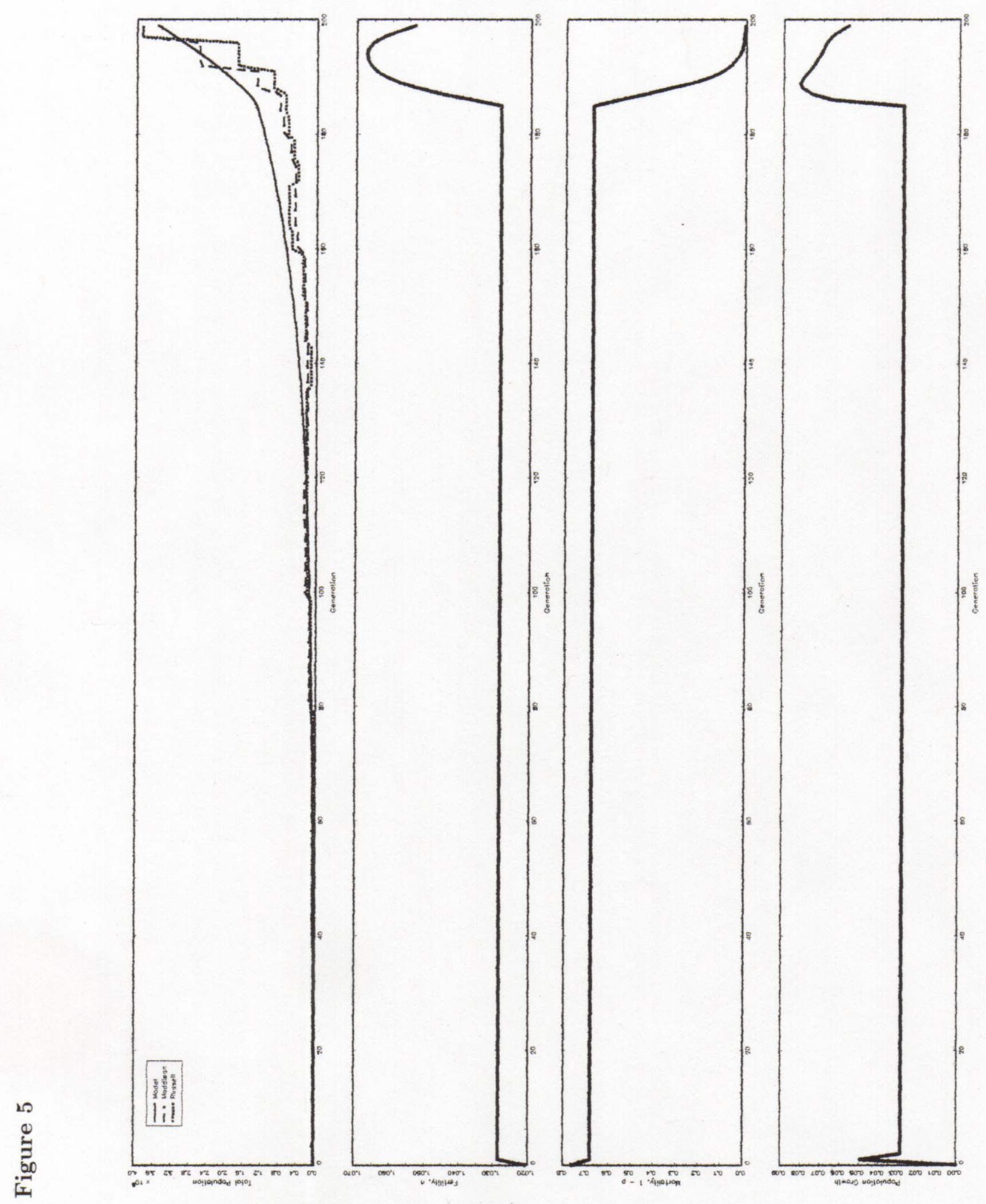

우 

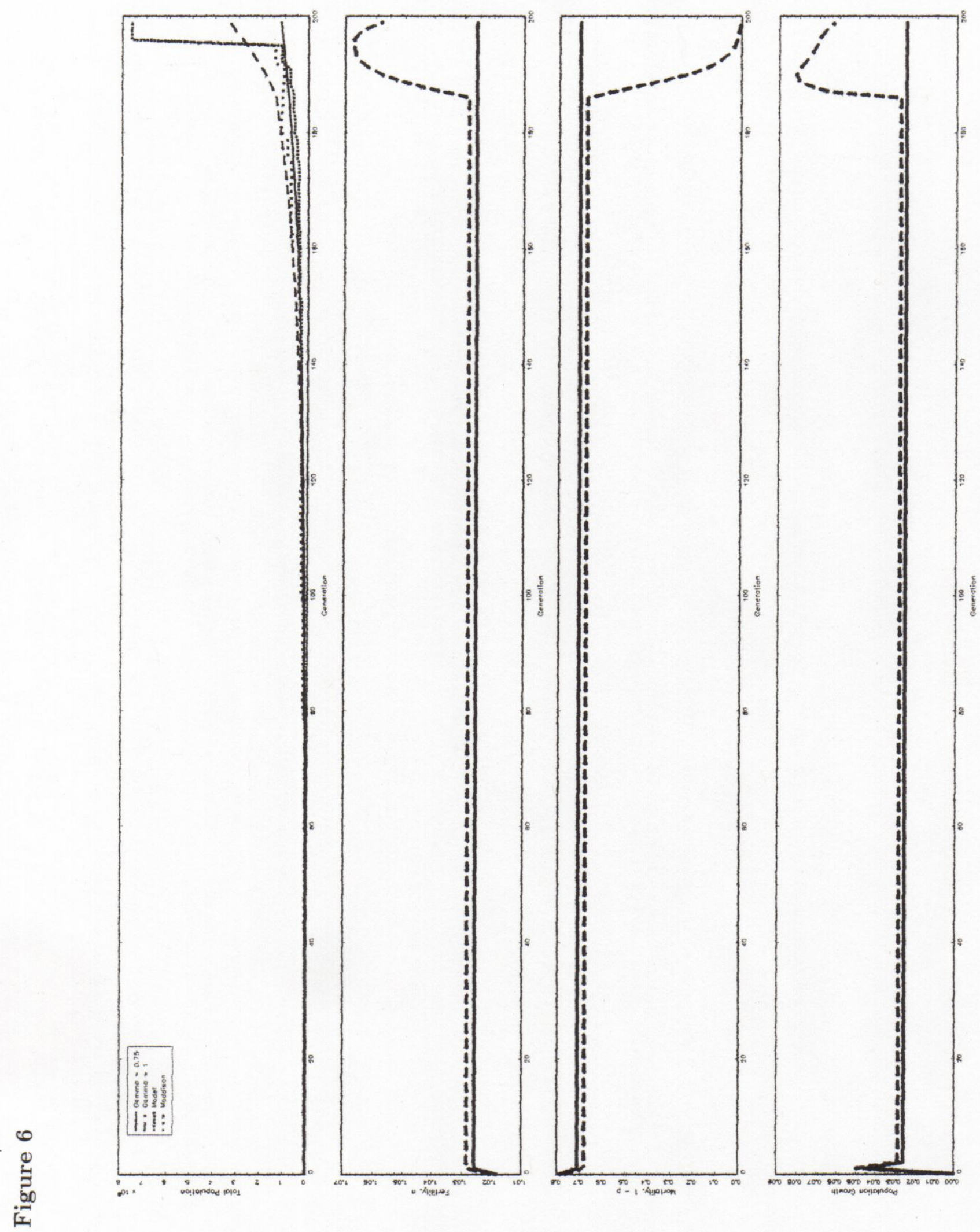
Figure 7:

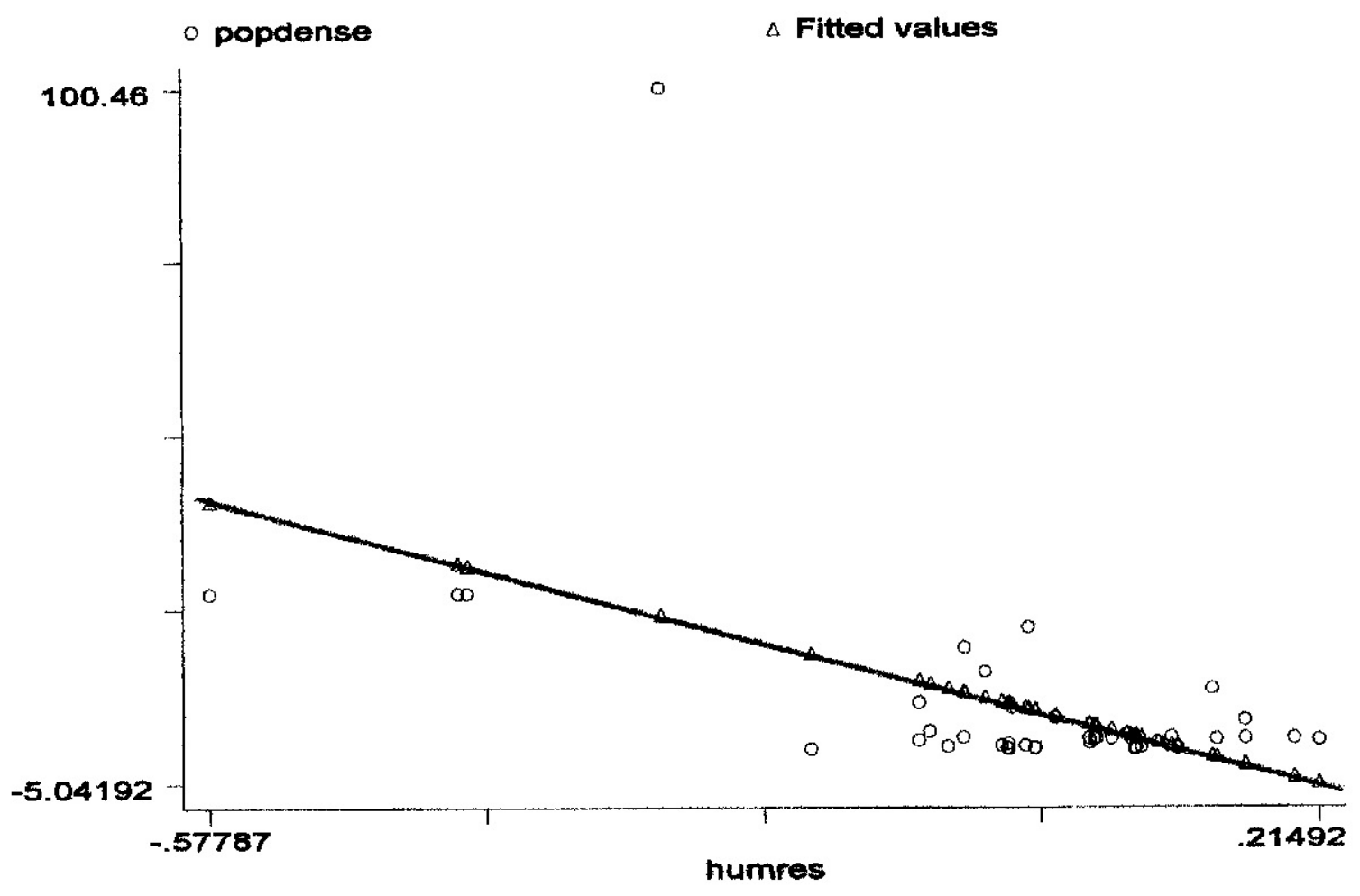


Table 1: Parameter Choices and Initial Value of State Variables

\begin{tabular}{|c|c|c|c|c|c|}
\hline Parameters & (a) & (b) & (c) & (d) & (e) \\
\hline$G$ & 1 & 0.6 & 1.1 & 1 & 0.75 \\
\hline$\tau^{n}$ & 0.30 & 0.30 & 0.30 & 0.297475 & 0.297475 \\
\hline$\tau^{e}$ & 0.10 & 0.10 & 0.10 & 0.1025 & 0.1025 \\
\hline$\alpha$ & 0.75 & 0.75 & 0.75 & 0.75 & 0.75 \\
\hline$\beta$ & 0.75 & 0.75 & 0.75 & 0.749375 & 0.749375 \\
\hline$\gamma$ & 0.75 & 0.75 & 0.75 & 0.50 & 0.50 \\
\hline$\lambda$ & 1 & 1 & 1 & 1 & 1 \\
\hline$\theta$ & 0.50 & 0.50 & 0.50 & 0.40 & 0.40 \\
\hline$\delta$ & 0.25 & 0.25 & 0.25 & 0.25 & 0.25 \\
\hline$\eta$ & 0.05 & 0.05 & 0.05 & 0.075 & 0.075 \\
\hline$\psi$ & $10^{4}$ & $10^{4}$ & $10^{4}$ & $10^{4}$ & $10^{4}$ \\
\hline$v$ & 0.25 & 0.25 & 0.25 & 0.25 & 0.25 \\
\hline$L^{*}$ & 100,000 & 100,000 & 100,000 & $35,000,000$ & $35,000,000$ \\
\hline & & & & & \\
\hline \multicolumn{6}{|l|}{ State Variables } \\
\hline$A_{0}$ & 0.1 & 0.1 & 0.1 & 0.1 & 0.1 \\
\hline$e_{0}$ & 0 & 0 & 0 & 0 & 0 \\
\hline$L_{0}$ & 10,000 & 10,000 & 10,000 & 228,000 & 224,000 \\
\hline
\end{tabular}


Table 2.a: Western European Population Data

\begin{tabular}{|c|c|c|c|}
\hline Year & $\begin{array}{c}\text { Maddison* } \\
\text { (in millions) }\end{array}$ & $\begin{array}{c}\text { Russell** } \\
\text { (in millions) }\end{array}$ & $\begin{array}{l}\text { World Pop. Growth }{ }^{* * *} \\
\text { (a.a.r. over prec. period) }\end{array}$ \\
\hline-3000 & n.a. & n.a. & 0.000693 \\
\hline-2000 & n.a. & n.a. & 0.000657 \\
\hline-1000 & n.a. & n.a. & 0.000616 \\
\hline-500 & n.a. & n.a. & 0.001386 \\
\hline-200 & n.a. & n.a. & 0.001352 \\
\hline 0 & 24.700 & n.a. & 0.000626 \\
\hline 200 & n.a. & n.a. & 0.000556 \\
\hline 400 & n.a. & n.a. & 0 \\
\hline 500 & n.a. & 21.000 & n.a. \\
\hline 600 & n.a. & n.a. & 0.000256 \\
\hline 650 & n.a. & 14.500 & n.a. \\
\hline 800 & n.a. & n.a. & 0.000477 \\
\hline 1000 & 25.413 & 29.000 & 0.000931 \\
\hline 1100 & n.a. & n.a. & 0.001886 \\
\hline 1200 & n.a. & n.a. & 0.001178 \\
\hline 1300 & n.a. & n.a. & 0 \\
\hline 1340 & n.a. & 60.500 & n.a. \\
\hline 1400 & n.a. & n.a. & -0.000282 \\
\hline 1450 & n.a. & 41.500 & n.a. \\
\hline 1500 & 57.268 & n.a. & 0.001942 \\
\hline 1600 & 73.778 & n.a. & 0.002487 \\
\hline 1700 & 81.460 & n.a. & 0.001127 \\
\hline 1800 & n.a. & n.a. & 0.003889 \\
\hline 1820 & 132.888 & n.a. & n.a. \\
\hline 1900 & n.a. & n.a. & 0.005909 \\
\hline 1913 & 261.007 & n.a. & n.a. \\
\hline 1950 & 305.060 & n.a. & n.a. \\
\hline 1998 & 388.399 & n.a. & 0.011884 \\
\hline
\end{tabular}

* Source: Maddison (2001).

** $\quad$ Source: Russell (1972).

$* * *$ Source: Jones (2001). 
Table 2.b: Western European Population Estimates (in millions)

\begin{tabular}{||c||c|c|c|c||}
\hline \hline Year & $\begin{array}{c}\text { (a) } \\
\text { I }\end{array}$ & $\begin{array}{c}\text { (b) } \\
\text { Maddison* }\end{array}$ & $\begin{array}{c}\text { (c) } \\
\text { II }\end{array}$ & $\begin{array}{c}\text { Russell } \\
\text { (** }\end{array}$ \\
\hline-3000 & 0.519 & n.a. & 0.392 & n.a. \\
\hline-2000 & 1.541 & n.a. & 1.144 & n.a. \\
\hline-1000 & 3.943 & n.a. & 2.980 & n.a. \\
\hline-500 & 12.844 & n.a. & 9.705 & n.a. \\
\hline-200 & 21.608 & n.a. & 16.328 & n.a. \\
\hline 0 & 24.700 & 24.700 & 18.665 & n.a. \\
\hline 200 & 17.750 & n.a. & 21.000 & n.a. \\
\hline 400 & 17.750 & n.a. & $\ldots$ & n.a. \\
\hline 500 & $\ldots$ & n.a. & 21.000 & 21.000 \\
\hline 600 & 18.708 & n.a. & 11.042 & n.a. \\
\hline 650 & $\ldots$ & n.a. & 14.500 & 14.500 \\
\hline 800 & 20.681 & n.a. & $\ldots$ & n.a. \\
\hline 1000 & 25.413 & 25.413 & 29.000 & 29.000 \\
\hline 1100 & 41.859 & n.a. & 53.373 & n.a. \\
\hline 1200 & 47.448 & n.a. & 60.500 & n.a. \\
\hline 1300 & 47.448 & n.a. & 60.500 & n.a. \\
\hline 1340 & $\ldots$ & n.a. & 60.500 & 60.500 \\
\hline 1400 & 46.147 & n.a. & $\ldots$ & n.a. \\
\hline 1450 & $\ldots$ & n.a. & 41.500 & 41.500 \\
\hline 1500 & 57.268 & 57.268 & 49.559 & n.a. \\
\hline 1600 & 73.778 & 73.778 & 61.885 & n.a. \\
\hline 1700 & 81.460 & 81.460 & 68.859 & n.a. \\
\hline 1800 & $\ldots$ & n.a. & 95.638 & n.a. \\
\hline 1820 & 132.888 & 132.888 & $\ldots$ & n.a. \\
\hline 1900 & $\ldots$ & n.a. & 152.151 & n.a. \\
\hline 1913 & 261.007 & 261.007 & 175.657 & n.a. \\
\hline 1950 & 305.060 & 305.060 & 250.808 & n.a. \\
\hline 1998 & 388.399 & 388.399 & 388.399 & 388.399 \\
\hline \hline & & & & \\
\hline
\end{tabular}

* Source: Maddison (2001).

** Source: Russell (1972). 
Table 3.a: African Population Data

\begin{tabular}{|c|c|c|c|}
\hline Year & $\begin{array}{c}\text { Maddison* } \\
\text { (in millions) } \\
\end{array}$ & $\begin{array}{c}\text { Biraben* } \\
\text { (in millions) }\end{array}$ & $\begin{array}{l}\text { World Pop. Growth** } \\
\text { (a.a.r. over prec. period) }\end{array}$ \\
\hline-3000 & n.a. & n.a. & 0.000693 \\
\hline-2000 & n.a. & n.a. & 0.000657 \\
\hline-1000 & n.a. & n.a. & 0.000616 \\
\hline-500 & n.a. & n.a. & 0.001386 \\
\hline-200 & n.a. & n.a. & 0.001352 \\
\hline 0 & 16.500 & 26.000 & 0.000626 \\
\hline 200 & n.a. & n.a. & 0.000556 \\
\hline 400 & n.a. & n.a. & 0 \\
\hline 500 & n.a. & n.a. & n.a. \\
\hline 600 & n.a. & n.a. & 0.000256 \\
\hline 650 & n.a. & 14.500 & n.a. \\
\hline 800 & n.a. & n.a. & 0.000477 \\
\hline 1000 & 33.000 & 39.000 & 0.000931 \\
\hline 1100 & n.a. & n.a. & 0.001886 \\
\hline 1200 & n.a. & n.a. & 0.001178 \\
\hline 1300 & n.a. & n.a. & 0 \\
\hline 1340 & n.a. & 60.500 & n.a. \\
\hline 1400 & n.a. & n.a. & -0.000282 \\
\hline 1450 & n.a. & n.a. & n.a. \\
\hline 1500 & 46.000 & 87.000 & 0.001942 \\
\hline 1600 & 55.000 & 113.000 & 0.002487 \\
\hline 1700 & 61.000 & 107.000 & 0.001127 \\
\hline 1800 & n.a. & 102.000 & 0.003889 \\
\hline 1820 & 74.200 & n.a. & n.a. \\
\hline 1900 & 110.000 & 138.000 & 0.005909 \\
\hline 1913 & 124.700 & n.a. & n.a. \\
\hline 1950 & 228.300 & 219.000 & n.a. \\
\hline 2000 & 759.954 & 759.954 & 0.011884 \\
\hline
\end{tabular}

* Source: Maddison (2001).

** Source: Jones (2001). 
Table 3.b: African Population Estimates (in millions)

\begin{tabular}{||c||c|c|c|c||}
\hline \hline Year & $\begin{array}{c}\text { (a) } \\
\text { III }\end{array}$ & $\begin{array}{c}\text { (b) } \\
\text { Maddison* }\end{array}$ & $\begin{array}{c}\text { (c) } \\
\text { IV }\end{array}$ & $\begin{array}{c}\text { (d) } \\
\text { Biraben* }\end{array}$ \\
\hline-3000 & 0.347 & n.a. & 0.547 & n.a. \\
\hline-2000 & 1.011 & n.a. & 1.594 & n.a. \\
\hline-1000 & 2.634 & n.a. & 4.150 & n.a. \\
\hline-500 & 8.580 & n.a. & 13.520 & n.a. \\
\hline-200 & 14.434 & n.a. & 22.745 & n.a. \\
\hline 0 & 16.500 & 16.500 & 26.000 & 26.000 \\
\hline 200 & 23.050 & n.a. & 22.905 & n.a. \\
\hline 400 & 23.050 & n.a. & 27.240 & n.a. \\
\hline 500 & $\ldots$ & n.a. & $\ldots$ & n.a. \\
\hline 600 & 24.293 & n.a. & 28.710 & n.a. \\
\hline 650 & $\ldots$ & n.a. & $\ldots$ & n.a. \\
\hline 800 & 26.855 & n.a. & 31.738 & n.a. \\
\hline 1000 & 33.000 & 33.000 & 39.000 & 39.000 \\
\hline 1100 & 33.622 & n.a. & 63.590 & n.a. \\
\hline 1200 & 38.112 & n.a. & 72.082 & n.a. \\
\hline 1300 & 38.112 & n.a. & 72.082 & n.a. \\
\hline 1340 & $\ldots$ & n.a. & $\ldots$ & n.a. \\
\hline 1400 & 37.067 & n.a. & 70.105 & n.a. \\
\hline 1450 & $\ldots$ & n.a. & $\ldots$ & n.a. \\
\hline 1500 & 46.000 & 46.000 & 87.000 & 87.000 \\
\hline 1600 & 55.000 & 55.000 & 113.000 & 113.000 \\
\hline 1700 & 61.000 & 61.000 & 107.000 & 107.000 \\
\hline 1800 & $\ldots$ & n.a. & 102.000 & 102.000 \\
\hline 1820 & 74.200 & 74.200 & $\ldots$ & n.a. \\
\hline 1870 & 90.500 & 90.500 & $\ldots$ & n.a. \\
\hline 1900 & 110.000 & 110.000 & 138.000 & 138.000 \\
\hline 1950 & 228.300 & 228.300 & 216.700 & 216.700 \\
\hline 1998 & 759.954 & 759.954 & 759.954 & 759.954 \\
\hline \hline & & & & \\
\hline
\end{tabular}

* Source: Maddison (2001). 
Table 4: OLS and Robust Regressions

Dependent Variable: POPULATION DENSITY, 1,500 A. D. (Person/Square km.)

\begin{tabular}{||l|l|l|l|l|l|l||}
\hline \hline & $(1)$ & $(2)$ & $(3)$ & $(4)$ & $(5)$ & $(6)$ \\
\hline LATITUDE & 13.11 & $\ldots$ & 23.71 & $-93.51^{* *}$ & $\ldots$ & 37.01 \\
\hline & $(17.40)$ & & $(16.52)$ & $(42.27)$ & & $(233.9)$ \\
\hline TEMP $P_{j}$ & $\ldots$ & 5.06 & 11.94 & $\ldots$ & $7.61^{* *}$ & $7.92^{* * *}$ \\
\hline & & $(12.77)$ & $(13.48)$ & & $(3.77)$ & $(4.65)$ \\
\hline HUMID $D_{t}$ & $\ldots$ & $-52.77^{*}$ & $-54.20^{*}$ & $\ldots$ & $-32.59^{*}$ & $-32.26^{*}$ \\
\hline & & $(14.31)$ & $(14.14)$ & & $(4.24)$ & $(4.62)$ \\
\hline MINERAL & $\ldots$ & -9.83 & -9.35 & $\ldots$ & -3.89 & -4.03 \\
\hline & & $(12.33)$ & $(12.16)$ & & $(3.65)$ & $(3.75)$ \\
\hline LLOCK $K_{j}$ & $\ldots$ & -6.50 & -5.48 & $\ldots$ & -3.00 & -3.00 \\
\hline & & $(8.85)$ & $(8.75)$ & & $(2.62)$ & $(2.66)$ \\
\hline & & & & & & \\
\hline No. of obs. & 42 & 42 & 42 & 42 & 42 & 42 \\
\hline$R^{2}$ & .014 & .286 & .325 & $\ldots$ & $\ldots$ & $\ldots$ \\
\hline \hline
\end{tabular}

Note: ${ }^{*}, * *, * * *$ respectively denote significance at the 1 percent, 5 percent, and 10 percent levels. Columns (4)-(6) show robust regression results. 